\title{
TRANSIÇÃO MIGRATÓRIA E URBANA NO ESTADO DO ESPÍRITO SANTO - 1950 a 2010
}

\author{
Aurélia Herminia Castiglioni \\ Universidade Federal do Espírito Santo - UFES \\ Programa de Pós-Graduação em Geografia \\ aurelia.castiglioni@gmail.com
}

\begin{abstract}
RESUMO
Os efeitos das transformações socioeconômicas e dos percursos dos processos de transição ocorridos no Espírito Santo, a partir da metade do século XX, resultaram em novos modelos migratórios e de urbanização. Este estudo se propõe a analisar a progressão e as modificações nos modelos de migração e de urbanização no Espírito Santo, em particular na Região Metropolitana da Grande Vitória - RMGV, decorrentes da evolução conjunta do processo de desenvolvimento e das transições demográfica, migratória, urbana e econômica, na segunda metade do século XX e início do século atual. A análise dos níveis, da evolução dos processos focalizados e de suas inter-relações é feita a partir de indicadores demográficos construídos com dados censitários produzidos pelo Instituto Brasileiro de Geografia e Estatística - IBGE. Os resultados mostram que a dinâmica demográfica do Espírito Santo evoluiu da fase caracterizada por crescimento elevado da população e acentuada migração rural-urbana a uma nova etapa, de redução conjunta do crescimento natural ou vegetativo, dos movimentos rural-urbanos e do crescimento da população da Região Metropolitana da Grande Vitória, atualmente cenário de forte migração intra e interurbana e de deslocamentos para trabalho e estudo, que ocorrem principalmente entre os municípios que a formam.
\end{abstract}

Palavras-chave: Migração e urbanização. Transformações nos padrões demográficos. Região Metropolitana da Grande Vitória. Processos de transição.

\section{MIGRATORY AND URBAN TRANSITION IN THE STATE OF ESPIRITO SANTO 1950 to 2010}

\section{ABSTRACT}

The effects of the socio economic changes and the transitions processes pathways that occurred in the state of Espirito Santo as of first half of the $20^{\text {th }}$ century resulted in new migration and urbanization patterns. This paper aims at analyzing the development and changes in the migration and urbanization patterns occurred in Espirito Santo, in particular in Greater Vitoria Metropolitan Region - GVMR - caused by the joint evolution of the development process and demographic, migratory, urban and economic transitions that took place in the second half of the $20^{\text {th }}$ century and beginning of the current one. The analysis of the level, the focused processes evolution and their interrelations is carried out based on indicators constructed with census data produced by the Instituto Brasileiro de Geografia e Estatística - IBGE, The results show that the demographic dynamics of Espirito Santo have developed from the stage characterized by high population growth and intense rural-urban migration to a slow-down phase of the natural increase, of the rural-urban movement and the growth of the Greater Vitoria Metropolitan Region, which currently presents a strong scenario of intra and inter urban migration, and commuting from and to its municipalities.

Keywords: Migration and urbanization. Demographic pattern changes. Greater Vitoria Metropolitan Region. Transitions processes.

\section{INTRODUÇÃO}

A redistribuição da população e a expansão das cidades são características da "Revolução demográfica", processo marcado por alterações relevantes nos níveis e nos comportamentos dos componentes demográficos, que ocorreu no bojo de uma série de transformações vivenciadas pela sociedade a partir do século XVIII em várias áreas. A evolução dos padrões demográficos é observada universalmente, as mudanças concentraram-se nos séculos XVIII e XIX nos países

$\begin{array}{lllll}\text { Caminhos de Geografia } \quad \text { Uberlândia } & \text { v. 20, n. } 72 & \text { Dez/2019 } & \text { p. 33-53 Página } 33\end{array}$


atualmente desenvolvidos; no século XX entraram em cena os países em desenvolvimento, que se apresentam em diversas fases dos processos de transição.

As alterações no comportamento dos componentes do crescimento natural ou vegetativo compõem o processo da transição demográfica. A queda diferencial dos níveis da mortalidade e da natalidade produz inicialmente a acentuação do crescimento demográfico e, à proporção que o processo avança, registra-se a desaceleração do ritmo de crescimento e a modificação progressiva da estrutura etária da população (LANDRY, 1934; NOTESTEIN, 1945).

Paralelamente, registram-se mudanças nos padrões da migração e da urbanização. A mobilidade apresentou no último século uma intensidade crescente, provocando modificações significativas nos modelos de distribuição da população, cujas características mais importantes são a rápida urbanização, a forte concentração da população nos maiores centros urbanos, e no senso oposto, a consequente drenagem das regiões rurais.

Bairoch em seu trabalho sobre a história da urbanização e suas relações com a economia nas diversas sociedades, analisa a magnitude do crescimento urbano associado a um crescimento demográfico sem precedentes, que ocorreu nos países em desenvolvimento durante o século XX. $O$ autor destaca que se trata de "uma verdadeira inflação urbana", um fenômeno inédito na história da urbanização pela sua magnitude, causas e consequências (BAIROCH, 1985, p. 547). Bairoch (1985) compara os diferentes ritmos de crescimento urbano ocorridos nos dois blocos de países, que ele denomina Mundo Desenvolvido e Terceiro Mundo. A passagem da taxa de urbanização de 12 para $32 \%$ levou cerca de 100 anos nos países do Mundo Desenvolvido, enquanto que no Terceiro Mundo esta evolução se efetuou em 50 anos. A "explosão urbana" ocorreu, em particular, após a segunda guerra mundial (Figura 1).

Figura 1 - Proporção de população urbana nas Regiões mais desenvolvidas e nas Regiões menos desenvolvidas - 1950 a 2050.

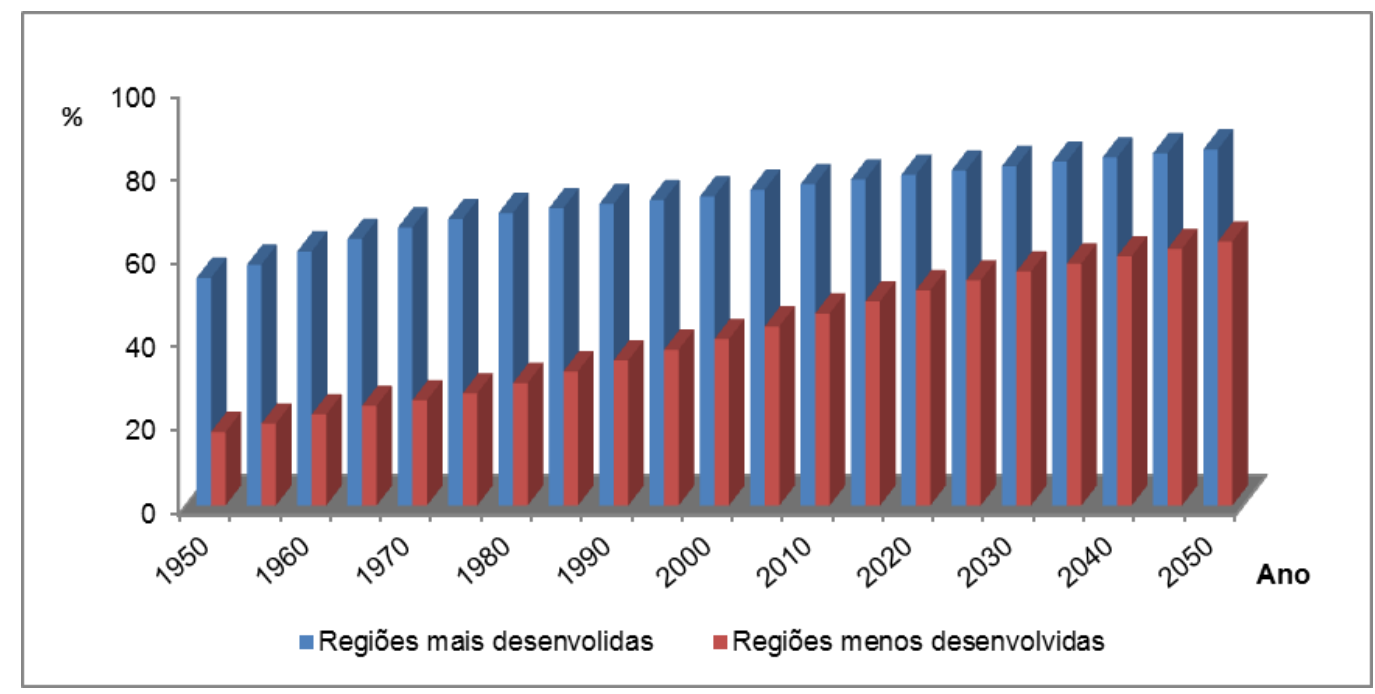

Fonte - Elaborado com dados da UNITED NATIONS (2015).

Nota: As Regiões mais desenvolvidas compreendem a Europa, América do Norte, Austrália, Nova Zelândia e Japão; as Regiões menos desenvolvidas compreendem todas as regiões da África, Ásia (exceto Japão), América Latina e Caribe, Melanesia, Micronesia e Polinesia.

Em 1900, 10\% da população mundial viviam nas áreas urbanas, a proporção passou para $29,6 \% \mathrm{em}$ 1950, tornando-se majoritária em 2007 (UNITED NATIONS, 2015). Observa-se atualmente a desaceleração do crescimento das grandes cidades, todavia a marcha da urbanização continua em sua tendência crescente: a proporção de pessoas que vivem nas regiões urbanas das Regiões mais desenvolvidas evoluiu de 54,6\% em 1950 para 78,3\% em 2015; nos países das Regiões menos desenvolvidas o indicador passou de 17,6 para $49,0 \%$. As diferenças entre os níveis de urbanização das Regiões mais e menos desenvolvidas declinam: as projeções mostram em 2050 os níveis de urbanização nessas regiões serão respectivamente de 85,4 e $63,4 \%$, indicando que as diferenças se

$\begin{array}{lllll}\text { Caminhos de Geografia } \quad \text { Uberlândia } & \text { v. 20, n. } 72 \quad \text { Dez/2019 } & \text { p. 33-53 } & \text { Página } 34\end{array}$


reduzem gradualmente de 37 pontos percentuais em 1950 para 29,3 em 2015 e 22,0 em 2050 (UNITED NATIONS, 2015).

A maioria da população urbana já vive nos países em desenvolvimento que formam um conjunto heterogêneo quanto aos níveis do processo, em 2015, nesses países, viviam cerca de 3 dentre os 4 bilhões de pessoas que habitavam as áreas urbanas do planeta (UNITED NATIONS, 2015). Segundo as projeções das Nações Unidas, $66,4 \%$ da população mundial residirão nas áreas urbanas em 2050, e o crescimento ocorrerá, sobretudo nos países em desenvolvimento onde habitarão 5,231 dentre os 6,341 bilhões de habitantes dessas áreas (UNITED NATIONS, 2015).

O processo de urbanização, impulsionado por fatores demográficos como também por causas sociais, econômicas e políticas, apresenta características fortemente diferenciadas entre os dois blocos de países. Os processos de urbanização e desenvolvimento dos países atualmente desenvolvidos mostram-se inter-relacionados, Golini (2003) ressalta que a urbanização iniciada com a revolução industrial, que se desenvolveu por cerca de 100 a 200 anos

favoreceu a transição demográfica e dessa se alimentou de maneira gradual e progressiva; se beneficiou, nos países europeus, da possibilidade da emigração internacional em direção aos novos continentes para eliminar na justa medida e no momento certo o excedente de população (e diminuir, assim, a pressão demográfica sobre a cidade) (GOLINI, 2003, p. 126, tradução nossa).

O autor ressalta que nesses países, no final da década de 1950, esgota-se o sistema constituído pela tríade industrialização-urbanização-migração, devido principalmente à "cidade central, que se torna cada vez mais ingovernável e antieconômica, seja do ponto de vista produtivo, como humano" (GOLINI, 2003, p. 127, tradução nossa). Ao longo das décadas da segunda metade do século XX as grandes cidades desses países apresentaram redução no ritmo de crescimento e mesmo diminuição da população.

Comparando os processos ocorridos nos dois blocos de países, Véron argumenta que "o fenômeno da urbanização parece ser de outra natureza nos países em desenvolvimento; ele teria se tornado largamente autônomo" (VÉRON, 2006, p. 63, tradução nossa). A "explosão urbana", que tomou impulso após a segunda guerra mundial, foi possibilitada pela conjugação do crescimento urbano com os efeitos da rápida transição demográfica vivenciada por esses contextos. Ao contrário do que ocorreu no primeiro bloco, a urbanização dos países em desenvolvimento não foi beneficiada por oportunidades polícias, econômicas e sociais, produzindo um excesso de urbanização, gerando "um forte desequilíbrio em todas as relações demográfico-econômicas” (GOLINI, 2003, p.129, tradução nossa).

As teorias focalizadas a seguir objetivam fundamentar a análise da evolução dos padrões migratórios e urbanos que ocorrem no Espírito Santo, seus níveis, fatores e inter-relações.

Com relação ao processo de transição migratória, Wilbur Zelinsky (1971) argumenta que um ponto fundamental a ser destacado é que a mobilidade não é propriamente paralela ao processo comumente denominado transição demográfica, mas que estes processos compõem um sistema evolutivo mais amplo. Zelinsky denomina o processo decorrente da mudança dos comportamentos dos componentes do crescimento natural ou vegetativo como "vital transition" enquanto que as modificações da mobilidade constituem a transição migratória. A verdadeira e completa transição demográfica agrupa as transições "vital" e migratória.

O autor faz uma análise das mudanças observadas nos padrões demográficos, ocorridos durante o processo de modernização da sociedade e postula a existência de associação estreita desses, no tempo espaço, com a evolução das transições "vital" e da mobilidade (ZELINSKY, 1971).

Zelinsky (1971) destaca a importância da transição migratória como um processo de propagação de novos comportamentos demográficos de formas mais simples, como as migrações residenciais tradicionais de natureza matrimonial ou marcial, para formas mais complexas que incluem a circulação e a mobilidade virtual. Nas fases iniciais do processo de mudança demográfica predomina a migração rural-urbana, impulsora de forte redistribuição da população das pequenas comunidades rurais e interioranas rumo às maiores cidades. Com o prosseguimento do processo de transição, a migração rural-urbana decresce enquanto que as migrações interurbanas crescem em importância. A

$\begin{array}{lllll}\text { Caminhos de Geografia } & \text { Uberlândia } & \text { v. 20, n. } 72 & \text { Dez/2019 } & \text { p. 33-53 Página } 35\end{array}$


evolução do processo de desenvolvimento induz a modernização dos meios e da infraestrutura de transporte e de comunicação, possibilitando que as pessoas se desloquem mais facilmente para estudar ou trabalhar em outra comunidade, sem que haja necessidade de mudar de residência. No cenário urbano tornam-se cada vez mais frequentes os movimentos pendulares, deslocamentos regulares entre a residência e os locais de trabalho ou estudo, assim como a intensificação da circulação constituída por uma diversidade de movimentos de "curto período, repetitivos ou cíclicos" (ZELINSKY, 1971, p. 17), realizados por vários motivos, sobretudo econômicos e de lazer. Em estágios mais avançados, desenvolve-se a mobilidade virtual.

A teoria de Zelinsky apresenta fragilidades decorrentes das hipóteses de base da teoria que não se verificam universalmente no tempo e no espaço, problema que é também comum às outras teorias de transição. A evolução histórica dos diferentes contextos em que ocorrem os processos apresenta especificidades, dificultando a apreensão da complexidade dos fenômenos demográficos por modelos de aplicação universal, "argumento particularmente válido em um país desigual e populoso como o Brasil", como argumentam Rigotti et al com respeito à migração (RIGOTTI et al., 2017, p. 9). Trata-se, no entanto, de uma teoria de grande amplitude, que busca apreender a evolução espacial e temporal da mobilidade em suas inter-relações com os processos demográficos e de evolução da sociedade (PEIXOTO, 2007).

O processo de transição urbana traduz as etapas da modificação da distribuição espacial da população que, principiando de um nível baixo de urbanização eleva-se progressivamente, torna-se majoritariamente urbana, prosseguindo até chegar a um patamar estável e elevado de concentração urbana (VRIES, 1995; PUMAIN, 2003; VÉRON, 2006). A modificação do grau de urbanização, indicado pela proporção de população urbana, toma a forma de uma curva logística. Em certo nível elevado de urbanização, em que grande parte da população vive nas cidades, o ritmo do crescimento tende a se reduzir, tornar-se quase nulo, e a se estabilizar.

São observadas associações estreitas entre as fases da transição demográfica, da migração e da urbanização (VRIES, 1995). Na fase inicial da transição demográfica, marcada pela redução da mortalidade e preservação de níveis elevados de natalidade, ocorre um aumento rápido da taxa de crescimento e do tamanho da população. As sociedades tradicionais, caracterizadas por economia predominantemente agrária e por costumes, atitudes, normas e valores considerados tradicionais, apresentam elevada fecundidade, com modelos familiares caracterizados por número elevado de filhos, encontrando-se na fase do processo, em que o crescimento natural ou vegetativo é o fator preponderante das mudanças demográficas (NOTESTEIN, 1945; LANDRY, 1934; CASELLI et al., 2001). O crescimento demográfico elevado produz um excedente de mão-de-obra rural, que é impelido a deslocar-se para outras regiões, provocando a aceleração da urbanização.

$\mathrm{Na}$ medida em que o processo de transição demográfica prossegue, registra-se a diminuição continuada da participação do componente natural ou vegetativo na evolução da população, e a migração torna-se o fator principal das modificações dos níveis e do sentido dos indicadores do crescimento demográfico e, em especial da rápida urbanização. Segundo o modelo de transição urbana, o indicador de urbanização prossegue em sua tendência de evolução crescente rumo a um nível elevado, quando se estabiliza (PUMAIN, 2003; VÉRON, 2006). Nesta fase acentua-se o crescimento das mobilidades inter e intra-urbana que se concentram nas maiores áreas urbanas.

No Brasil, as transformações decorrentes dos processos de transição marcaram o século $X X$, em particular a sua segunda metade, quando ocorreram mudanças relevantes nos níveis e nas características dos componentes demográficos, natalidade, mortalidade e migração, com consequências sobre o ritmo do crescimento, sobre a importância da contribuição dos componentes do crescimento e sobre a repartição espacial da população.

Este estudo focaliza os processos de migração e de urbanização, destacando a evolução dos padrões migratórios e suas inter-relações com o processo de redistribuição espacial da população no Espírito Santo verificado na segunda metade do século XX e início do século atual, em especial a expansão da Região Metropolitana da Grande Vitória - RMGV, principal área urbana do Estado, formada pela Capital Vitória e por Cariacica, Fundão, Guarapari, Serra, Viana e Vila Velha (Figura 2).

$\begin{array}{lllll}\text { Caminhos de Geografia Uberlândia } & \text { v. 20, n. } 72 \quad \text { Dez/2019 } & \text { p. 33-53 Página } 36\end{array}$


Os dados censitários do Instituto Brasileiro de Geografia e Estatística (IBGE) são utilizados para a construção de indicadores para mensurar e analisar a evolução, as características e correlações entre migração e urbanização no Espírito Santo.

Figura 2 - Espírito Santo e Região Metropolitana da Grande Vitória.

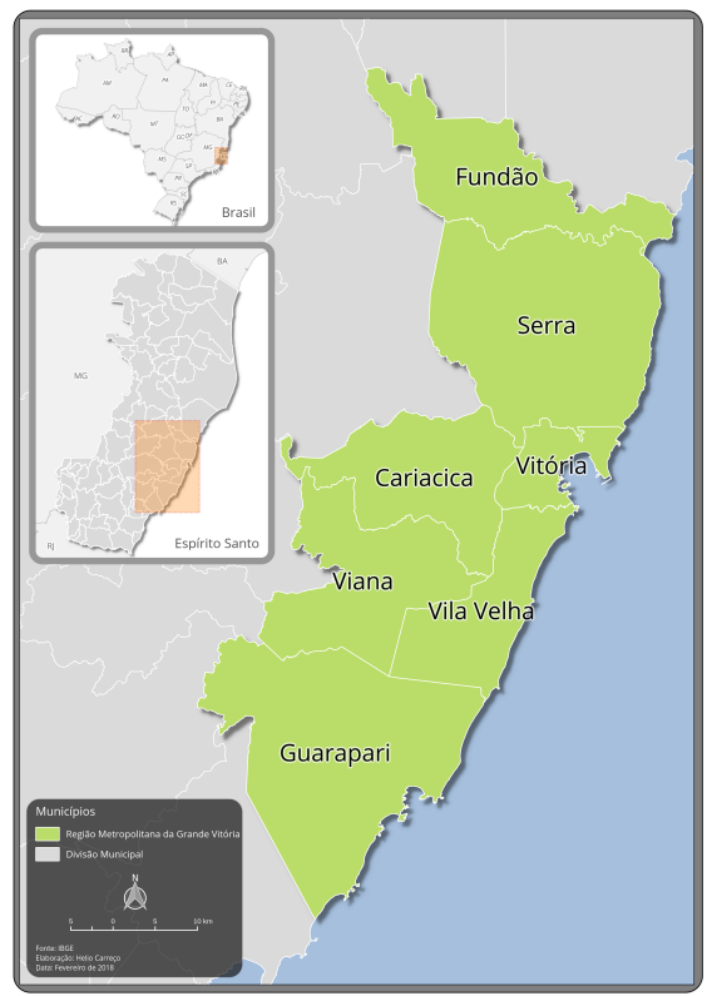

Fonte - Elaborado com base cartográfica do IBGE.

O Espírito Santo apresenta particularidades quanto à evolução dos padrões demográficos, comparado aos outros estados da Região Sudeste, em decorrência dos fatores históricos, políticos e econômicos que condicionaram a colonização e o povoamento do território. A ocupação do espaço evoluiu lentamente, o processo só se intensificou na segunda metade do século XIX, em consequência dos programas nacionais e locais elaborados para incentivar a imigração europeia, que se constituiu no mais importante vetor do crescimento da população do Espírito Santo (CASTIGLIONI, 2009a). O programa imigratório tinha por objetivo fixar famílias de agricultores na região rural e, para isto, facilitava aos imigrantes a aquisição das suas próprias "Colônias", propriedades pequenas ou médias onde as famílias se estabeleciam e permaneciam.

A segunda parte do século $X X$ foi marcada por mudanças conjunturais que produziram impactos importantes na estrutura econômica e social do Estado. A desagregação da economia agrária teve reflexos negativos para a grande parte dos municípios do Estado que por mais de um século tiveram suas estruturas socioeconômicas estreitamente vinculadas à economia do café, situação ainda vivenciada por grande parte dos municípios interioranos.

Ao lado dos fatores históricos políticos e econômicos, o fator demográfico desempenhou papel igualmente importante nessas transformações. O tipo peculiar de povoamento que ocorreu no Espírito Santo, assentado nos pilares formados pela imigração europeia, pequena propriedade, agricultura familiar e cultura do café praticada em um tipo de economia fechada voltada para a exportação, delineou a ocupação do território e imprimiu marcas na sociedade local, com bases fortemente rurais que se fizeram presentes no Estado até meados do século XX (CELIN, 1984; CASTIGLIONI, 2009a).

\begin{tabular}{lllll}
\hline Caminhos de Geografia $\quad$ Uberlândia & v. 20, n. 72 & Dez/2019 & p. 33-53 & Página 37
\end{tabular}


A transição de uma economia agroexportadora para urbano-industrial se anuncia na década de 1960, quando o Governo adota políticas para atrair capital nacional e externo objetivando dinamizar o desenvolvimento econômico do Estado. Os denominados "Grandes Projetos", expressão usualmente utilizada no Espírito Santo para denominar os projetos industriais financiados pelo grande capital, planejados para alavancar e reestruturar a estrutura econômica do Estado atraíram investimentos aplicados na década de 1970 e início da década de 1980, principalmente nos setores siderúrgico (Usinas de pelotização), paraquímico (produção de celulose) e portuário. Esta nova fase veio transferir a supremacia da região rural para a urbana, pois, os "Grandes Projetos" se concentraram na região da capital e suas proximidades, que apresentavam maiores facilidades de infraestrutura, induzindo também a concentração das atividades comerciais e dos serviços nessa região. Estas transformações produziram impactos sobre a distribuição espacial da população: a aceleração da urbanização em contraposição ao esvaziamento do campo e das pequenas cidades e vilas do interior.

É importante destacar as limitações que envolvem a conceituação da migração e da urbanização no estudo empírico desses processos. A migração, em definição ampla, designa os movimentos dos indivíduos de uma população tendo por finalidade a mudança de residência de um determinado lugar de origem para um determinado lugar de destino (COURGEAU, 1988; UNITED NATIONS, 2013). Entretanto, uma definição única não abarca a multiplicidade de aspectos que permeiam o fenômeno migratório. A definição da migração é limitada por problemas relacionados à diversidade de conceitos à base desse fenômeno como também por problemas técnicos relativos à dificuldade de levantamento de dados apropriados para a apreensão do seu dinamismo (CUNHA e PATARRA, 1987; COURGEAU, 1988; CARVALHO e RIGOTTI, 1998; CASTIGLIONI, 2009b). A urbanização, compreendida como o crescimento da proporção da população que vive nas áreas urbanas, tem como base nos vários países, uma diversidade de critérios demográficos, administrativos, econômicos ou a combinação de vários deles. O estudo da urbanização no Brasil, pautado nas definições oficiais, dificulta a caracterização das dimensões espaciais e temporais desse processo em um contexto heterogêneo e em transformação, onde, como ressalta Cunha "novas formas de assentamentos humanos passam a surgir, como fruto de mudanças nas relações econômicas e sociais entre o campo e a cidade" (CUNHA, 2005, p. 3).

Não obstante a problemática e os desafios inerentes ao processo de conceituação e de apreensão de fenômenos complexos e multifacetados, os dados censitários fornecem um rico panorama das dimensões dos fenômenos estudados.

\section{EVOLUÇÃO DA URBANIZAÇÃO NO ESPÍRITO SANTO}

O rápido processo de urbanização vivenciado pelo Espírito Santo ao longo da segunda metade do século XX decorreu da ação de fatores fortemente expulsores que agiam na região rural, associados a fatores que operavam nas áreas urbanas, como a industrialização, o crescimento das atividades terciárias, a modernização e expansão dos meios e da infraestrutura de transporte e de comunicação (CASTIGLIONI, 2009a).

Na sociedade de traços fortemente rurais que prevalecia no Espírito Santo nos meados do século XX, a urbanização ocorreu com atraso, comparativamente ao nível médio do país (CASTIGLIONI, 2009a). A proporção de população urbana do Brasil (Figura 3) atingiu 31,2\% em 1940; no Espírito Santo o valor do índice era de 20,0\% (IBGE, 1951). Em 1950, não existiam aglomerações urbanas importantes no Estado, o indicador do país avança para 36,2\%, enquanto que no Estado, o nível da urbanização pouco evoluiu, passando a 20,8\% (IBGE, 1955). O geógrafo Pasquale Petrone, em estudo sobre a área de colonização antiga no Espírito Santo, feito nos meados do século XX, ressalta a "quase inexistência de verdadeiros nódulos de população, dentro do conjunto de típica dispersão", e 
qualifica como "falta de vocação urbana" (PETRONE, 2004, p.76, 77) o tipo de povoamento da região, marcado pela dispersão do habitat e pelo isolamento dos habitantes das zonas rurais.

O Brasil passou a ser predominantemente urbano durante a década de 1960, no Espírito Santo a população urbana só se tornou preponderante ao longo da década de 1970, crescendo acentuadamente nas décadas seguintes. Ao final da primeira década do presente século, o nível de urbanização de 83,4\%, converge para o nível médio do país. (IBGE, 1973, 2012).

Figura 3 - Evolução da proporção de população urbana do Brasil e do Espírito Santo - 1940 a 2010.

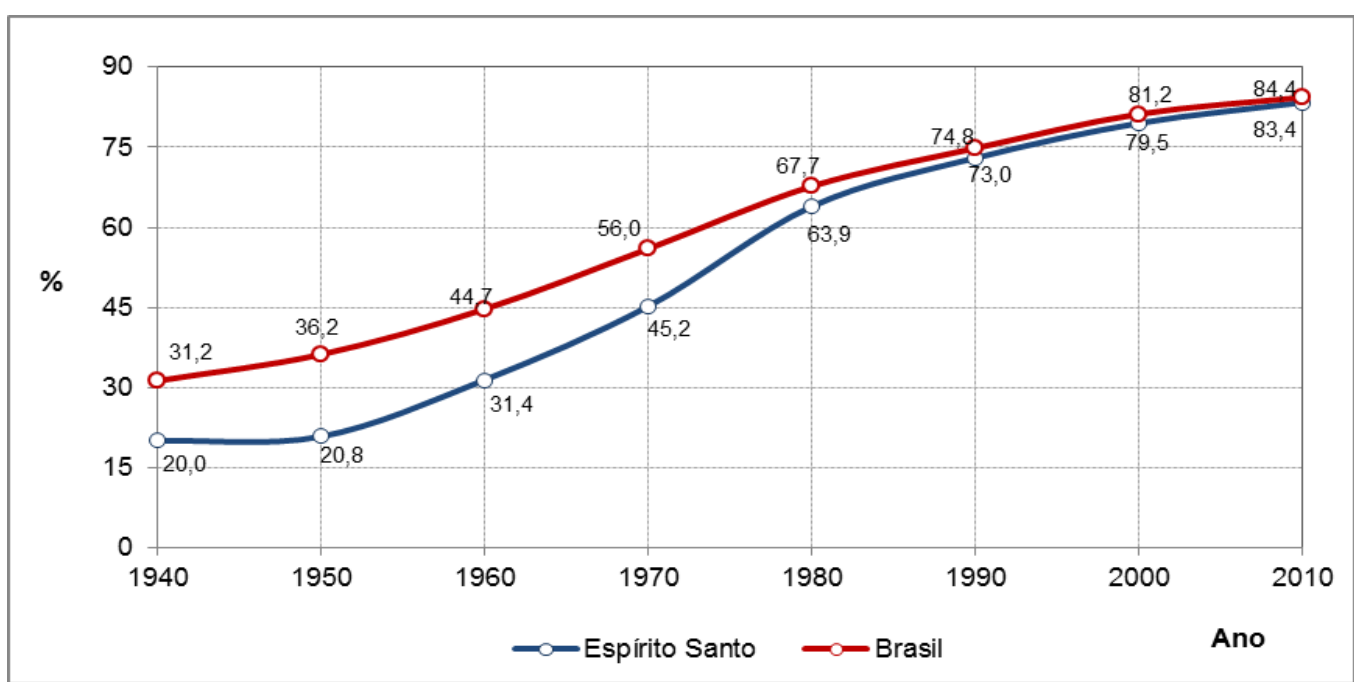

Fonte - Elaborado com dados do IBGE (1951, 1955, 1968, 1973, 1982, 1996, 2001, 2012); CASTIGLIONI (2009a).

A evolução da população residente nas regiões urbanas no Espírito Santo apresenta as características da curva logística que traduz o processo de transição urbana, com crescimento elevado a partir de 1960, seguido da desaceleração do ritmo nas últimas décadas. A população do Estado, de 790.149 habitantes em 1940 chega a 3.514 .952 em 2010 (IBGE, 1951, 2012). Nesse período o número de habitantes da área urbana passa de 157.925 a 2.931 .472 , enquanto que a população rural, de 632.224 habitantes em 1940, declina gradativamente a partir da década de 1970 reduzindo-se a 583.480 habitantes em 2010 (IBGE, 1951, 2012). A população rural se reduziu em $7,7 \%$ enquanto que a da região urbana foi multiplicada por 18,6 .

A evolução das taxas de crescimento no período de 1940 a 2010 (Figura 4) coloca em evidência os modelos distintos de crescimento vivenciados pela população rural e urbana ao longo de período considerado. A forma da curva dessas taxas reflete, sobretudo, o ritmo da migração rural-urbana, com tendência inicial crescente e redução nas últimas décadas.

As primeiras décadas do período analisado foram marcadas por crescimento demográfico acelerado decorrente da queda da mortalidade e da manutenção dos níveis elevados de fecundidade (CASTIGLIONI, 2009a). O indicador de fecundidade, de mais de 7 filhos por mulher, um dos mais elevados do Brasil, mostra o potencial de crescimento da população e a importância da contribuição do componente natural ou vegetativo para a formação do "excedente de mão-de-obra" que se constituiu na região rural (IBGE, 1992).

Na primeira etapa, relativa ao início do período analisado, os níveis de crescimento das regiões rural e urbana eram próximos, todavia a transferência populacional já se anunciava nas taxas mais elevadas de crescimento urbano.

Na segunda fase, de 1950 a 1980, a migração rural-urbana toma impulso, provocando modificações importantes na distribuição espacial da população e tornando-se o principal vetor da rápida urbanização que ocorria no Estado. As causas destas mudanças foram preponderantemente, fatores que impeliam a população a deixar a zona rural e o interior do Estado e, por outro lado, fatores

$\begin{array}{lllll}\text { Caminhos de Geografia } \quad \text { Uberlândia } & \text { v. 20, n. } 72 & \text { Dez/2019 } & \text { p. 33-53 Página } 39\end{array}$


atrativos representados por atividades econômicas, que começaram a se concentrar e dinamizar a região da capital (CASTIGLIONI, 2009a). Neste cenário, a ação dos fatores repulsivos precedeu a dos atrativos, pois os investimentos para a instalação de importantes projetos industriais passaram a ser aplicados nos finais da década de 1960 e no decorrer da década de 1970, ademais, a ação dos fatores expulsores operantes na zona rural foi preponderante para a impulsão da migração ruralurbana e para o crescimento da urbanização (CASTIGLIONI, 1989). Este tipo de evolução corrobora a análise feita por Bairoch (1985) sobre a especificidade das causas da expansão da urbanização nos países em desenvolvimento. Segundo o autor, ao contrário do que ocorreu no bloco dos países desenvolvidos, o crescimento urbano dos países em desenvolvimento "se realizou praticamente sem desenvolvimento econômico, sem industrialização, e o que é ainda mais grave, sem aumento da produtividade agrícola" (BAIROCH, 1985, p.652).

Figura 4 - Taxa média geométrica de crescimento anual da população do Espírito Santo, segundo a situação do domicílio (\%) - 1940/1950 a 2000/2010.

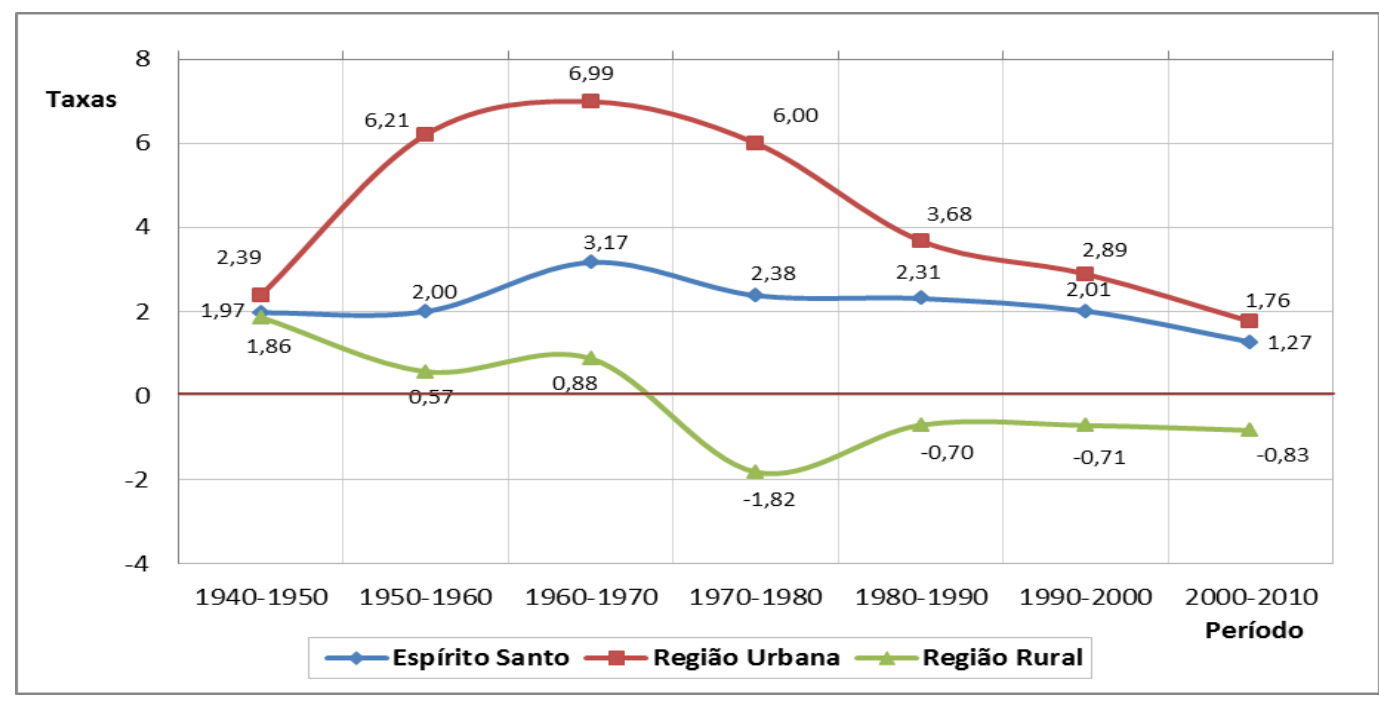

Fonte - Elaborado com dados do IBGE (1951, 1955, 1968, 1973, 1982, 1996, 2001, 2012).

Nessa fase, as diferenças de crescimento entre regiões se acentuam, com tendências opostas para as duas regiões, enquanto que as taxas de crescimento urbano atingem níveis de 6,0 a 7,0\%, nas regiões rurais o crescimento evolui para valores negativos, indicando claramente que migração ruralurbana está em curso e se acentua, impulsionando o crescimento da urbanização. As diferenças atingem seus níveis máximos durante as décadas de 1960 e 1970, quando as taxas de crescimento urbano atingem seus maiores níveis (CASTIGLIONI, 2009a). Tendência contrária é observada na região rural, cujas taxas de crescimento apresentam baixos valores positivos no período de 1950 a 1970, resultantes do efeito da fecundidade da população que compensava parte das perdas migratórias, evoluindo a seguir, para valores negativos, que atingem o valor mínimo, de $-1,82 \%$ na década de 1970, traduzindo perdas migratórias significativas. Nessa década, 20 dentre os 53 municípios do Espírito Santo apresentaram diminuição em seus efetivos populacionais, mesmo que os níveis declinantes, porém ainda elevados de fecundidade, de 6,4 filhos por mulher em 1970 e de 4,3 em 1980 (IBGE, 1992), assegurassem uma participação importante dessa componente do crescimento natural ou vegetativo. Os indicadores de migração mostram mais radicalmente as perdas populacionais vivenciadas pela maioria dos municípios do Estado: 39 dentre 53 municípios apresentaram saldos migratórios negativos na década (CASTIGLIONI, 1989).

$\mathrm{Na}$ terceira fase, correspondente às três últimas décadas, as transformações nos padrões dos componentes do crescimento natural ou vegetativo prosseguem em sua tendência clássica. A transição demográfica apresenta-se então na fase de redução conjunta dos níveis da natalidade e da mortalidade, cujas taxas tendem a níveis próximos, reduzindo a participação desse componente no crescimento do Estado. O ritmo das migrações rurais-urbanas também diminui, em consequência da redução dos efetivos populacionais do interior drenados pela migração anterior, como também pela desaceleração do ritmo do crescimento natural da população. O traço principal da mobilidade das últimas décadas passa a ser a intensificação da migração interurbana e dos deslocamentos

$\begin{array}{lllll}\text { Caminhos de Geografia } \quad \text { Uberlândia } & \text { v. 20, n. } 72 & \text { Dez/2019 } & \text { p. 33-53 } & \text { Página } 40\end{array}$


pendulares que ocorrem nas principais áreas urbanas. O crescimento urbano continua positivo e superior à média do Estado, enquanto que a população rural segue em sua tendência decrescente. Os valores negativos das taxas de crescimento, após o período de grande evasão, são mantidos, a exemplo do que ocorre nos países desenvolvidos desde o fim da segunda guerra mundial, em consequência da abertura dos mercados, da especialização das culturas, da mecanização e do progresso dos métodos agrícolas que diminuem as necessidades de mão-de-obra (MERLIN, 1997; GOLINI, 2003).

A figura 5 mostra a evolução do nível de urbanização nos municípios do Espírito Santo entre 1970 e 2010. Em 1970 níveis elevados de urbanização, superiores a 98\%, são apresentados pelas cidades mais antigas, Vitória e Vila Velha, seguidas por Cariacica, situadas na RMGV. Fora desta área destacam-se poucos centros urbanos com níveis médios de urbanização, dentre os quais as principais cidades do Sul e do Norte, Cachoeiro de Itapemirim e Colatina. O mapa de 2010 destaca a acentuação da urbanização que ocorreu no período focalizado em todo o Estado. Em 1970, 83,0\% dos municípios se classificavam como predominantemente rurais; em 2010, somente 25,6\% dos municípios conservam essa denominação.

Como ocorre em muitos países em desenvolvimento, a concentração da população na principal região urbana representa um traço importante do processo de urbanização do Espírito Santo. A proporção dos habitantes do Estado que viviam nos municípios da atual RMGV se eleva de 15,2\% em 1950 a 48,0\% em 2010 (IBGE, 1955, 2012). Os índices de urbanização, superiores a 90\% para a maior parte dos municípios da região atingem 100\% em Vitória e Vila Velha.

Figura 5 - Proporção da População Urbana nos Municípios do Espírito Santo - 1970 e 2010.

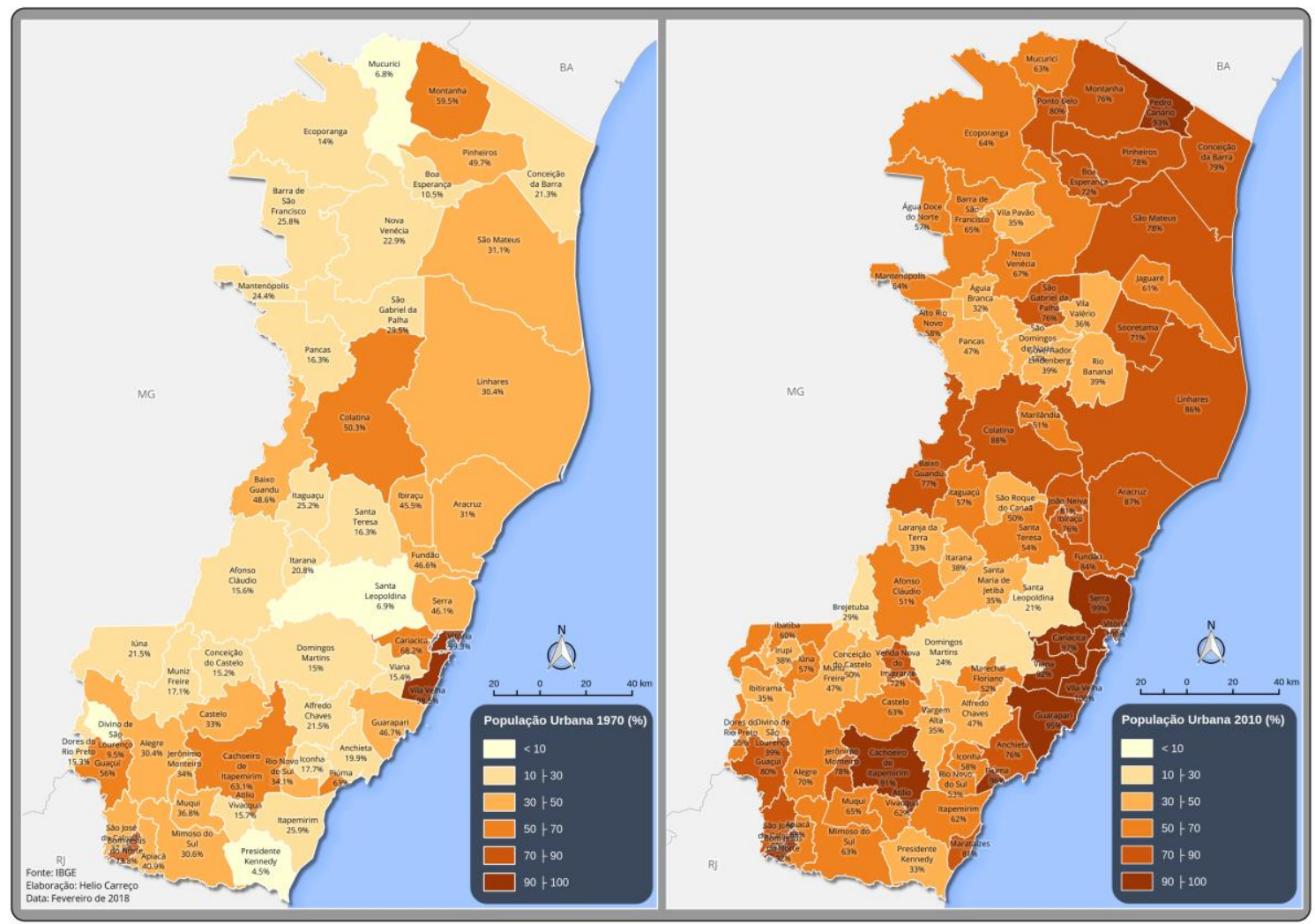

Fonte - Elaborado com dados do IBGE $(1973,2012)$.

O Mapa de 2010 coloca também em evidência a persistência das desigualdades históricas dos níveis de urbanização e de desenvolvimento existentes entre a região litorânea, mais urbanizada, e a região do interior. Os municípios litorâneos, em número de 15, situados nas Microrregiões: RMGV, Litoral Sul, Rio Doce e Nordeste concentram 59,8\% da população e 79,6\% do PIB do Espírito Santo em 2010 (IBGE, 2012; IJSN, 2012; BRASIL et al, 2013). 


\section{CARACTERÍSTICAS DA MOBILIDADE NO ESPÍRITO SANTO}

Os dados censitários referentes ao lugar de nascimento das pessoas residentes em determinado local possibilitam o estudo do estoque de migrantes, resultante do acúmulo dos fluxos migratórios ocorridos no passado. O segmento das pessoas não naturais, compreendido como a população que reside em município diferente daquele de nascimento corresponde, em 2010 , a $42,9 \%$ da população do Estado. Considerando-se a migração interestadual, o número de pessoas nascidas em outras Unidades da Federação passou de 14,1\% a 18,6\% da população do Estado entre 1970 e 2010 (Tabela 1).

Como preconizam Ravenstein (1889) e vários autores dos modelos matemáticos, estatísticos e gravitacionais que utilizam variáveis relativas ao espaço geográfico: distância, população, superfície, para explicar e prever a migração observa-se forte relação entre distância e volume migratório (CASTIGLIONI, 2009b). Na composição do estoque de migrantes do Espírito Santo predominam pessoas oriundas dos estados próximos. Os migrantes originários dos estados vizinhos, Minas Gerais, Bahia, Rio de Janeiro representavam 92,5\% da categoria dos não naturais em 1970; a representação desses migrantes passou para $83,4 \%$ em 2010 indicando a ampliação do leque de origem das imigrações. Os mineiros, historicamente os mais numerosos, contavam por $9,5 \%$ da população do Estado em 1970, reduzindo-se para 8,2\% em 2010. Com tendência contrária, a representação do grupo dos baianos, o grupo que mais cresce, dobrou entre 1970 e 2010, subindo de $2,2 \%$ a $4,5 \%$.

Tabela 1 - Pessoas não naturais do Espírito Santo segundo os principais estados de nascimento 1970 a 2010.

\begin{tabular}{|c|c|c|c|c|c|c|c|c|}
\hline \multirow{3}{*}{ Ano } & \multirow{3}{*}{$\begin{array}{c}\text { Pessoas } \\
\text { não } \\
\text { naturais } \\
\text { do ES }\end{array}$} & \multirow{3}{*}{$\begin{array}{c}\text { Pessoas } \\
\text { não } \\
\text { naturais } \\
\text { do ES } \\
(\%)\end{array}$} & \multicolumn{6}{|c|}{ Estado de nascimento das pessoas não naturais do ES } \\
\hline & & & \multicolumn{2}{|c|}{ Minas Gerais (\%) } & \multicolumn{2}{|c|}{ Bahia (\%) } & \multicolumn{2}{|c|}{ Rio de Janeiro (\%) } \\
\hline & & & $\begin{array}{l}\text { sobre } \\
\text { ES }\end{array}$ & $\begin{array}{l}\text { sobre } \\
\text { Não } \\
\text { Naturais }\end{array}$ & $\begin{array}{c}\text { Sobre } \\
\text { ES }\end{array}$ & $\begin{array}{c}\text { sobre } \\
\text { Não } \\
\text { Naturais }\end{array}$ & $\begin{array}{c}\text { sobre } \\
\text { ES }\end{array}$ & $\begin{array}{l}\text { sobre } \\
\text { Não } \\
\text { Naturais }\end{array}$ \\
\hline 1970 & 225.699 & 14,14 & 9,46 & 66,89 & 2,21 & 15,64 & 1,41 & 10,00 \\
\hline 1980 & 332.151 & 16,45 & 10,16 & 61,76 & 2,26 & 13,74 & 2,33 & 14,18 \\
\hline 1991 & 463.457 & 17,84 & 9,80 & 54,92 & 2,87 & 16,06 & 2,76 & 15,49 \\
\hline 2000 & 587.852 & 19,00 & 9,28 & 48,82 & 3,96 & 20,86 & 2,98 & 15,70 \\
\hline 2010 & 648.520 & 18,56 & 8,21 & 44,24 & 4,45 & 23,96 & 2,81 & 15,15 \\
\hline
\end{tabular}

Fonte - Elaborado com dados do IBGE (1973, 1982, 1997, 2001, 2012); CASTIGLIONI e BRASIL (2008).

O número de pessoas nascidas no Espírito Santo, residentes em outras Unidades da Federação, monta a 497.788 em 2010. Esse contingente dirigiu-se principalmente para dois eixos. O primeiro é composto pelas correntes que migraram para estados próximos, Rio de Janeiro $(36,1 \%)$ que exerceu grande influência sobre a sociedade local, seguido por Minas Gerais (17,2\%), São Paulo $(10,1 \%)$ e Bahia $(6,8 \%)$. No outro eixo, de mobilidade de longa distância, dirigido para a exploração das atividades extrativas e agrárias, destaca-se Rondônia, com o terceiro maior número de capixabas $(14,0 \%)$, que atraiu pequenos e médios proprietários nas décadas de grande evasão rural, vindo a seguir o Pará $(3,5 \%)$.

As informações coletadas nos últimos censos sobre o local de residência anterior " $x$ " anos antes da data de referência da pesquisa fornecem medidas da migração de data fixa, isto é, do fluxo migratório decorrente da comparação entre o lugar de residência " $x$ " anos atrás, com o lugar de residência na data do censo (CARVALHO; RIGOTTI, 1998).

Nos meados do século XX o Espírito Santo apresentava perdas migratórias. Os fluxos emigratórios dirigiam-se, tal como evidenciado na análise dos não-naturais, para duas áreas principais: uma situada na Região Sudeste, englobando São Paulo e Rio de Janeiro, e outra formada por estados da Região Norte, Rondônia e Pará.

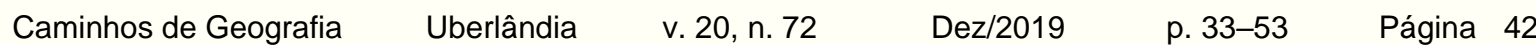


A tabela 2 contém os dados da migração registrada a partir de 1970, década caracterizada pelo advento dos chamados "Grandes projetos". As transformações da estrutura produtiva do Estado produziram a inversão da tendência migratória na década de 1980, quando o Espírito Santo passa a apresentar saldo positivo em suas trocas interestaduais (CASTIGLIONI, 2009a). A atratividade se consolida nas décadas seguintes em decorrência do bom desempenho da economia local, dinamizada pela expansão e diversificação das indústrias e dos portos, produção de minério de ferro e de aço, exploração do petróleo, do mármore, do granito, de produtos agrícolas com destaque da sempre presente economia do café, e de produtos hortigranjeiros. Em estudo sobre a migração no Espírito Santo, Dota aponta como uma das principais causas da dinamicidade da economia do Estado no período $2005-2010$ os "altos preços das commodities no mercado internacional e seus reflexos em investimentos e geração de empregos” (DOTA, 2016, p. 148).

Nas trocas migratórias interestaduais efetuadas no último quinquênio pesquisado, 2005-2010, as entradas no Espírito Santo totalizaram 130.820, as saídas, 70.120, resultando um saldo positivo de 60.700 migrantes. As trocas internas envolveram 171.081 pessoas. A RMGV e o grupo formado pelos demais Municípios do Estado apresentam comportamentos diferenciais em suas dinâmicas migratórias. Os municípios que formam a RMGV apresentam saldos positivos nas migrações intra e interestaduais enquanto que o grupo formado pelos municípios não metropolitanos apresenta saldo negativo nas trocas intra-estaduais, mas positivo nos saldos interestaduais.

Com relação aos fluxos migratórios dos períodos de 1986-1991, 1995-2000 e 2005-2010, Dota (2016) coloca em evidência as mudanças ocorridas na evolução da dinâmica migratória dos municípios não metropolitanos nos referidos períodos, destacando que, com relação às trocas migratórias realizadas com a RMGV os saldos dos municípios situados fora da região permanecem negativos, porém com tendência de redução progressiva, enquanto que, no âmbito interestadual, ocorreu a inversão das trocas negativas registradas para esse conjunto nos períodos anteriores para saldos positivos no período de 2005-2010.

Tabela 2 - Imigração, emigração e saldos migratórios do Espírito Santo ocorridos nos períodos de 1970/1980, 1986/1991, 1995/2000 e 2005/2010.

\begin{tabular}{|r|c|c|c|c|}
\hline Período & Imigração & Emigração & $\begin{array}{c}\text { Saldos } \\
\text { Migratórios }\end{array}$ & $\begin{array}{c}\text { Índice de Eficácia } \\
\text { Migratória - IEM }\end{array}$ \\
\hline $\mathbf{1 9 7 0 - 1 9 8 0}(\mathbf{1})$ & 155.114 & 163.028 & -7.914 & $-0,0249$ \\
\hline $\mathbf{1 9 8 6 - 1 9 9 1}$ & 135.421 & 90.909 & 44.511 & 0,1967 \\
\hline $\mathbf{1 9 9 5 - 2 0 0 0}$ & 129.169 & 95.168 & 34.001 & 0,1516 \\
\hline $\mathbf{2 0 0 5 - 2 0 1 0}$ & 130.820 & 70.120 & 60.700 & 0,3021 \\
\hline
\end{tabular}

Fontes - IBGE(1982, 1996, 2001, 2012); CASTIGLIONI (1989); CASTIGLIONI; BRASIL ( 2008).

Notas: (1) Estimados por método indireto.

O Índice de Eficácia Migratória, dado pela razão entre migração líquida e volume migratório, permite avaliar os ganhos e perdas apresentados nas trocas migratórias realizadas entre uma determinada região e o conjunto de regiões (BAENINGER, 2000; OLIVEIRA et al., 2011). O indicador varia de -1 a +1 , quanto mais os valores do índice se aproximarem de -1 ou de +1 , maior é a capacidade de evasão ou de retenção migratória da região, valores próximos a zero indicam rotatividade migratória. Os valores do Índice de Eficácia Migratória mostram que o Espírito Santo evoluiu de um cenário classificado como área de rotatividade migratória, (1970/1980), para uma situação de baixa absorção migratória (1986/1991 e 1991/2000), tornando-se, no período de 2005-2010, área de média absorção migratória, com a quinta posição no ranking de absorção migratória no cenário Nacional (IBGE, 2012).

As trocas migratórias efetuadas entre o Espírito Santo e as Unidades da Federação, ocorridas no quinquênio 2005-2010 são, em sua maior parte, favoráveis ao Espírito Santo. Os maiores saldos migratórios decorrem, também neste quesito, das trocas realizadas com estados próximos, por ordem de importância: Bahia, Minas Gerais, Rio de Janeiro e São Paulo. Fora desta área, destacam-se os saldos das trocas efetuadas com Alagoas e Pará.

Dentre os fluxos migratórios originados no Estado, destacaram-se, com início na década de 1970, as migrações do norte do Espírito Santo em direção à Rondônia, principalmente para os municípios de

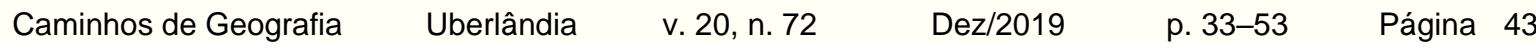


Cacoal, Ji-Paraná e Espigão d'Oeste (IBGE, 2012). Os fluxos eram compostos por famílias de agricultores que mantinham relações frequentes com as comunidades de origem, induzindo novas migrações de familiares e conhecidos. No último período analisado (2005-2010) ocorreu a inversão da tendência observada nas três últimas décadas do século $X X$, com um pequeno saldo em favor do Espírito Santo.

A Figura 6 apresenta Índices migratórios relativos ao quesito migração de data fixa do censo de 2010. O primeiro mapa contém os saldos migratórios dos municípios do Espírito Santo e o segundo, a razão entre o saldo da migração data-fixa e a população de 5 anos ou mais em 2010. Os indicadores expressam a inter-relação estreita existente entre migração, concentração de riqueza, de infraestrutura socioeconômica e de oportunidades de trabalho. A RMGV, que concentra 48\% da população e 63,2\% do PIB do Espírito Santo em 2010 (IJSN, 2012; IBGE, 2012), destaca-se como a principal região atrativa, com destaque para Serra, a unidade com maior saldo migratório, seguida por Vila Velha. Neste conjunto Vitória particulariza-se por apresentar saldo negativo elevado. A capital apresenta alto volume migratório, atrai grande número de migrantes, que se deslocam a seguir para outras unidades da região.

Fora da região da capital, destacam-se como pontos atrativos municípios situados no litoral norte, que apresentam novas atividades econômicas com aumento da oferta de empregos. Dentre estes se destacam Linhares, com participação de 3,30\% no PIB estadual, que apresenta desenvolvimento industrial, com ênfase na indústria moveleira, metalomecânica, petróleo e gás, culturas do café e mamão; Aracruz, que ocupa a quinta posição no ranking do PIB $(3,46 \%)$, polo de produção de celulose e de exploração de petróleo, e São Mateus, cuja economia gravita em torno da exploração do petróleo, das culturas de mamão e pimenta do reino, e da silvicultura. Outro conjunto atrativo tem na cafeicultura sua principal atividade, indicando que a importância histórica do café continua sólida: incluem-se nesse grupo Sooretama e São Gabriel da Palha, no norte; Irupi no sudoeste e Venda Nova do Imigrante, situada na região central serrana, considerada a capital nacional do agroturismo. Santa Maria de Jetibá, com produção hortigranjeira, integra o grupo de economia agrária. No litoral sul, destaca-se Piúma, balneário com economia baseada no processamento da pesca e no turismo.

Figura 6 - Saldos migratórios e Índices migratórios (por mil) dos municípios do Espírito Santo - 20052010.

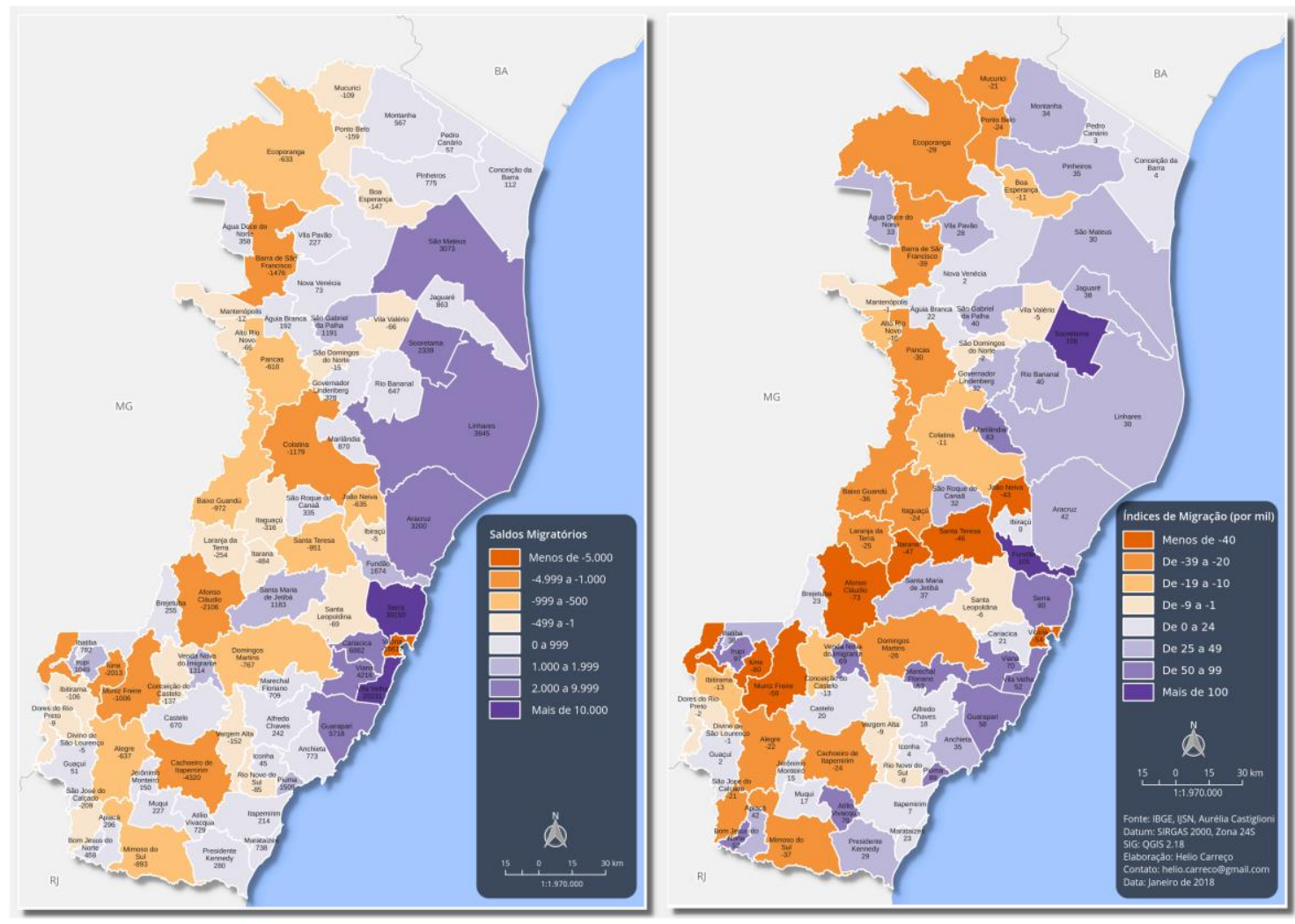

Fonte - Elaborado com dados do IBGE $(2012,2015)$. 
Os saldos migratórios apresentam valores negativos para 34 dentre os 78 municípios do Estado, dentre eles incluem-se dois antigos e importantes centros urbanos do Norte e do Sul, Colatina e Cachoeiro de Itapemirim. Excluindo-se Vitória, com comportamento particular, o grupo formado pelos municípios que apresentaram perdas populacionais teve redução na participação do PIB do Estado, que caiu de 16,14\% em 2000 a 11,67\% em 2010, quando 32 deles apresentaram declínio.

Quanto aos índices migratórios, controlado o efeito da população, aparecem como mais atrativos municípios menos populosos que se tornam dinâmicos: Sooretama, Fundão e Irupi. Os maiores valores negativos são registrados para lúna, Afonso Cláudio e Muniz Freire, situados na Região centro-oeste do Estado.

Assim como foi destacado para a urbanização, os mapas da figura 6 confirmam, com relação à migração, as diferenças existentes entre a região do litoral onde se concentram as unidades atrativas, e o interior, sobretudo no noroeste e no centro-oeste do Estado, com indicadores de repulsão que têm seus valores acentuados quando relacionados à população local.

De modo similar ao comportamento apresentado pela imigração, a emigração relativa ao fluxo data fixa oriundo do Espírito Santo teve como destinos principais estados próximos, Minas Gerais, Rio de Janeiro, Bahia e São Paulo, mas os saldos são positivos para o Espírito Santo.

$\mathrm{Na}$ teoria da Transição da Migração Zelinsky (1971) postula que, com o avanço do processo de modernização da sociedade, as fontes da migração rural-urbana se exaurem, enquanto que a melhoria da infraestrutura física e tecnológica possibilita a ampliação dos espaços de vivências das pessoas e a consequente intensificação de novas e mais complexas formas de mobilidade para trabalho, estudo, lazer. Os movimentos migratórios perdem intensidade em favor dos deslocamentos no espaço onde o indivíduo efetua suas diversas atividades. Segundo Courgeau a noção de espaço de vida "engloba não somente os lugares de passagem e de estadia, mais igualmente todos os outros lugares com os quais o indivíduo está em relação" (COURGEAU, 1988, p.17, tradução nossa).

Essas tendências constituem alterações verificadas na mobilidade do Espírito Santo no decorrer das últimas décadas, marcada pela intensificação de tipos de mobilidade que não requerem mudança de residência, em particular para trabalho e estudo. As dimensões reduzidas do Estado e a ocupação do espaço propiciam o incremento da mobilidade pendular entre os municípios, e destes com municípios de estados vizinhos.

Nos dois últimos censos foram levantadas informações sobre deslocamentos para trabalho ou estudo. Os dados do censo de 2000 indicam que 6,7\% das pessoas que estudavam ou trabalhavam no Brasil deslocavam-se para municípios diferentes daquele de residência. A Região Sudeste apresentava a maior intensidade dessa mobilidade, de 8,8\%, destacando-se o Rio de Janeiro com o maior índice do país (10,7\%), seguido pelo Espírito Santo (10,3\%).

O censo de 2010 oferece informações separadas sobre deslocamentos para estudo e para trabalho. A mobilidade pendular apresenta-se, como em 2000, mais intensa no Espírito Santo, em comparação ao país. Os deslocamentos para trabalho em outro município são praticados por $12,8 \%$ das pessoas ocupadas do Brasil, no Espírito Santo a representação desta categoria é de 17,7\%, o que lhe confere a segunda posição, após o Rio de Janeiro (17,8\%). Quanto aos deslocamentos para estudo em outro município, o Espírito Santo apresenta o segundo maior percentual dessa categoria (13,2\%), vindo após Santa Catarina (13,7\%).

A maior intensidade desses movimentos ocorre nas unidades administrativas que integram a RMGV e em suas proximidades, onde se concentram a população, a renda, os equipamentos socioeconômicos, as oportunidades de emprego, a infraestrutura de transporte.

\section{CONVERGÊNCIA DA MIGRAÇÃO PARA A RMGV}

O processo de expansão urbana no Brasil passou por sucessivas transformações em sua natureza. A metropolização, traço marcante e avançado desse processo, apresenta como traços principais o crescimento elevado das regiões urbanas, a expansão de suas áreas de influência e a reestruturação de seus espaços e funções.

No estudo sobre "Regiões de Influência das Cidades - REGIC 2007", o IBGE apresenta a categorização dos centros urbanos e a demarcação de seu espaço de influência, utilizando como critérios para categorização "a classificação dos centros de gestão do território, a intensidade de

$\begin{array}{lllll}\text { Caminhos de Geografia } \quad \text { Uberlândia } & \text { v. 20, n. } 72 & \text { Dez/2019 } & \text { p. 33-53 Página } 45\end{array}$


relacionamentos e a dimensão da região de influência de cada centro" (IBGE, 2008, p. 131). As cidades foram ordenadas em cinco categorias: Metrópoles - que reúne os 12 mais importantes centros urbanos do País; Capitais Regionais A, que agrupa 10 unidades, Capitais Regionais B ou C, em número de 21, Centros Sub-regionais, Centros de Zona ou Centros Locais, com 16 unidades (IBGE, 2008; RIBEIRO et al., 2012).

Ribeiro et al. ressaltam que no processo de metropolização "as transformações na natureza e na configuração espacial das cidades levam a distintos níveis de integração dos territórios a essa dinâmica" (RIBEIRO et al., 2012, p. 2). A rede de pesquisa do Observatório das Metrópoles utilizou indicadores das dimensões demográfica e socioeconômica para definir os níveis de integração utilizados para classificação dos municípios nas regiões metropolitanas. As unidades centrais constituem os polos, os municípios com elevada integração na dinâmica metropolitana classificam-se como extensão dos polos e os demais integrantes se classificam, segundo os níveis de integração, em grupos que variam em uma escala que compreende as categorias: "muito alto, alto, médio, baixo e muito baixo" (RIBEIRO et al., 2012, p. 20).

A RMGV foi criada em 1995, constituída pelos municípios de Cariacica, Serra, Viana, Vila Velha e Vitória. Em 1999 foi incluído o município de Guarapari e, em 2001 o município de Fundão (IJSN, 2005). A RMGV está incluída na categoria de Capitais Regionais $A$, que reagrupa áreas de influência regional. Na dinâmica da RMGV, o Polo, Vitória, e os municípios de Cariacica, Serra e Vila Velha apresentam nível de integração muito alto; Viana apresenta nível alto; Guarapari, médio e Fundão, nível baixo de integração (LIRA et al, 2014).

São examinadas a seguir características da mobilidade na região, considerando sucessivamente a migração de estoque, de data-fixa e os movimentos pendulares.

Com relação ao primeiro eixo da análise, na RMGV concentram-se $61,2 \%$ das pessoas nascidas em outas Unidades da Federação que residiam no Espírito Santo em 2010 (IBGE, 2015). A tabela 3 mostra que mais da metade das pessoas residentes na região em $2010(53,7 \%)$ nasceram em outros municípios, representação esta mais elevada que a média do Estado (42,9\%) (IBGE, 2015). A representação dos que nasceram em outras unidades da federação é de $24,3 \%$ população da Região em 2010.

Tabela 3 - População residente não natural em relação ao Município e à Unidade da Federação segundo os municípios da RMGV - 2010.

\begin{tabular}{|l|r|r|r|}
\hline Municípios da RMGV & $\begin{array}{c}\text { População não natural (\%) } \\
\text { não natural }\end{array}$ & $\begin{array}{c}\text { Em relação ao } \\
\text { Município }\end{array}$ & $\begin{array}{c}\text { Em relação à Unidade } \\
\text { da Federação }\end{array}$ \\
\hline Cariacica & 173.439 & 49,73 & 16,51 \\
\hline Fundão & 9.325 & 54,77 & 16,86 \\
\hline Guarapari & 54.068 & 51,35 & 29,66 \\
\hline Serra & 267.122 & 65,27 & 31,14 \\
\hline Viana & 36.888 & 56,75 & 16,99 \\
\hline Vila Velha & 217.814 & 52,54 & 25,59 \\
\hline Vitória & 148.136 & 45,19 & 22,24 \\
\hline RMGV & 906.792 & 53,73 & 24,25 \\
\hline
\end{tabular}

Fonte - Elaborado com dados do IBGE (2015).

A dinâmica migratória dos municípios da RMGV apresenta diversos modelos, decorrentes da evolução diferenciada do processo de concentração e expansão urbana. Na década de 1970, o crescimento dos municípios de povoamento mais antigo, Vitória, Vila Velha e Cariacica, se enfraquece em favor das unidades menos povoadas. Serra passa a ser deste então o município mais atrativo da Região (CASTIGLIONI, 2009a). Os dados do censo de 2010 indicam que 65,3\% da população residente em Serra não nasceram no município, sendo que quase um terço de sua

$\begin{array}{lllll}\text { Caminhos de Geografia } \quad \text { Uberlândia } & \text { v. 20, n. } 72 & \text { Dez/2019 } & \text { p. 33-53 } & \text { Página } 46\end{array}$


população nasceu fora do Estado (IBGE, 2012). Grande parte desse contingente migrou no decorrer das décadas de 1970 e 1980, quando o município tornou-se o local de implantação de indústrias multinacionais, como também por dispor de maior área para construção de habitações para absorção dos migrantes, vindos de fora como do interior do estado, em período de forte migração rural-urbana. Tendência contrária é apresentada pela capital, cujo crescimento é o mais baixo da região. Vitória é o menor município do Estado e também o mais densamente povoado, com 3.510,4 hab/ $/ \mathrm{Km}^{2} \mathrm{em} 2010$ (IBGE, 2012), a saturação do pequeno espaço da capital reduz a disponibilidade de imóveis e produz o aumento dos preços. A maior centralidade da capital age como fator atrativo para os migrantes que buscam oportunidades de trabalho e sociais, mas que, a seguir se dirigem para as áreas adjacentes buscando otimizar os custos que envolvem as relações entre as localizações dos lugares de trabalho e da moradia. Esta inversão das tendências do crescimento é geralmente apresentada pelas grandes áreas urbanas do país, a esse respeito Brito ressalta que o deslocamento que se observa no crescimento na região metropolitana, do Polo para outros municípios da região decorre da migração dos mais pobres entre essas áreas (BRITO, 2007).

A composição do segmento das pessoas não naturais do Estado, residentes na RMGV, guarda os traços observados no cenário estadual. Os mineiros constituem o grupo mais numeroso, contam por $41,4 \%$ das pessoas não naturais da região em 2010, com representação em declínio no período de 1980 a 2010, ao passo que representação dos baianos passou nesse período, de $10,8 \%$ a $24,1 \%$ (IBGE, 2015). A estrutura dos fluxos baianos apresenta muitas redes migratórias que, com relação ao local de origem, são compostas por grupos familiares e por grupos de amigos e conhecidos provenientes do mesmo local e, com relação ao local de destino, pela tendência de estabelecimento desses grupos em locais próximos.

O segundo eixo do estudo refere-se à migração de data fixa realizada por pessoas de cinco anos ou mais, que não residiam na RMGV em 31.07.2005. Os indicadores da tabela 4 mostram que a migração se intensifica nos municípios onde se concentram atividades econômicas e infraestruturas sociais e de transportes. Os quatro primeiros lugares no ranking da participação no PIB estadual são ocupados pelos municípios mais integrados na dinâmica metropolitana, por ordem: Vitória, que participa por $30,4 \%$ do PIB estadual, Serra (15,5\%), Vila Velha $(8,5 \%)$ e Cariacica $(6,0 \%)$ que apresentam os maiores volumes migratórios. Serra apresenta-se como a maior opção de residência para os imigrantes, já Vila Velha tem número elevado de entradas, como também de saídas. Vitória apresenta o maior volume migratório da RMGV, mas em sua composição predominam as saídas.

Tabela 4 - Imigrantes, Emigrantes, Saldo Migratório, Razão entre o Saldo Migratório e a População de 5 anos ou mais (por mil) e IEM - Municípios da RMGV - 2005-2010.

\begin{tabular}{|l|r|r|r|r|r|}
\hline $\begin{array}{c}\text { Municípios } \\
\text { da RMGV }\end{array}$ & Imigrantes & Emigrantes & $\begin{array}{c}\text { Saldo } \\
\text { migratório }\end{array}$ & $\begin{array}{c}\text { índice migratório } \\
\text { (Por mil) }\end{array}$ & $\begin{array}{c}\text { índice de Eficácia } \\
\text { Migratória }\end{array}$ \\
\hline Cariacica & 22.356 & 15.494 & 6.862 & 21,27 & 0,1813 \\
\hline Fundão & 2.816 & 1.142 & 1.674 & 105,49 & 0,4229 \\
\hline Guarapari & 12.234 & 6.516 & 5.718 & 58,38 & 0,3050 \\
\hline Serra & 45.636 & 15.486 & 30.150 & 80,04 & 0,4933 \\
\hline Viana & 7.273 & 3.055 & 4.218 & 69,93 & 0,4084 \\
\hline Vila Velha & 40.084 & 19.853 & 20.231 & 52,08 & 0,3375 \\
\hline Vitória & 29.824 & 46.442 & -16.617 & $-53,91$ & $-0,2179$ \\
\hline RMGV & $\mathbf{1 6 0 . 2 2 3}$ & $\mathbf{1 0 7 . 9 8 8}$ & $\mathbf{5 2 . 2 3 5}$ & $\mathbf{3 3 , 2 7}$ & $\mathbf{0 , 1 9 4 8}$ \\
\hline & \multicolumn{3}{|c|}{ Fonte - Elaborado com dados do IBGE (2015). } & \\
\hline
\end{tabular}

Os valores do Índice Migratório possibilitam a comparação dos saldos controlados do efeito do tamanho da população. Estes mostram que os municípios que foram assimilados mais recentemente na dinâmica de metropolização da RMGV apresentam índices mais elevados de atratividade, Fundão passa a ocupar a primeira posição neste ranking, seguido em ordem de valores por Serra, Viana e Guarapari. Considerando os valores do Índice de Eficiência Migratória, a RMGV classifica-se na

$\begin{array}{llllll}\text { Caminhos de Geografia } & \text { Uberlândia } & \text { v. 20, n. } 72 & \text { Dez/2019 } & \text { p. 33-53 } & \text { Página } 47\end{array}$


categoria de baixa absorção migratória, seus municípios se inserem em 3 categorias: Fundão, Viana, Guarapari, Vila Velha e Serra classificam-se como áreas de média absorção, Cariacica, como área de baixa absorção, e Vitória caracteriza-se como área de baixa evasão migratória.

A tabela 5 contém as entradas relativas à imigração de data-fixa (2005-2010) nas unidades que formam a RMGV, indicando a contribuição dos fluxos segundo a origem: imigração oriunda dos municípios do Estado e de outros estados do país, com representações bem próximas.

A análise das entradas verificadas no período 2005-2010 coloca em evidência as transformações que os padrões da migração apresentaram no período analisado: (a) a migração interestadual torna-se praticamente equivalente à migração interna; (b) a migração entre os municípios integrantes da RMGV $(30,46 \%)$ se torna superior à migração procedente dos demais municípios do Estado $(20,53 \%)$, tendência esta contrária à apresentada pelo Estado no período de 1950 a 1990, marcado pela redistribuição da população da região rural e municípios interioranos em direção à região da capital e a outros estados.

Tabela 5 - Imigração de data-fixa nos Municípios da RMGV segundo a origem dos fluxos (\%) - 20052010.

\begin{tabular}{|c|c|c|c|c|c|}
\hline \multirow{2}{*}{$\begin{array}{l}\text { Municípios } \\
\text { da RMGV }\end{array}$} & \multirow{2}{*}{$\begin{array}{l}\text { Imigração } \\
\text { Total }\end{array}$} & \multicolumn{3}{|c|}{ Imigração proveniente dos Municípios do ES (\%) } & \multirow{2}{*}{$\begin{array}{l}\text { Imigração } \\
\text { proveniente } \\
\text { de outros } \\
\text { Estados (\%) }\end{array}$} \\
\hline & & Total & $\begin{array}{l}\text { Municípios da } \\
\text { RMGV }\end{array}$ & $\begin{array}{l}\text { Outros } \\
\text { Municípios-ES }\end{array}$ & \\
\hline Cariacica & 22.356 & 64,54 & 40,16 & 24,38 & 35,46 \\
\hline Fundão & 2.816 & 76,28 & 41,59 & 34,69 & 23,72 \\
\hline Guarapari & 12.234 & 38,39 & 20,99 & 17,40 & 61,61 \\
\hline Serra & 45.636 & 46,60 & 29,09 & 17,50 & 53,40 \\
\hline Viana & 7.273 & 76,45 & 58,69 & 17,75 & 23,55 \\
\hline Vila Velha & 40.084 & 43,72 & 27,44 & 16,29 & 56,28 \\
\hline Vitória & 29.824 & 53,93 & 25,29 & 28,64 & 46,07 \\
\hline RMGV & 160.223 & 51,00 & 30,46 & 20,54 & 49,00 \\
\hline
\end{tabular}

Fonte - Elaborado com dados do IBGE $(2012,2015)$.

A matriz migratória (Tabela 6) contém as trocas realizadas entre os Municípios da RMGV relativas à migração de data fixa. Serra e Vila Velha são os principais destinos das migrações intra-regionais, absorvendo respectivamente $27,2 \%$ e $22,5 \%$ dos fluxos ocorridos no período. Já as saídas intraregionais de migrantes ocorrem com maior frequência em Vitória, representando $33,7 \%$ do total. Os fluxos mais intensos envolvem Vitória, Serra, Vila Velha e Cariacica, que apresentam nível de integração qualificado como muito alto na dinâmica regional. Os maiores fluxos intra-regionais são os movimentos migratórios de Vitória com destino a Serra e a Vila Velha, destacam-se também pelo volume os fluxos de Cariacica dirigidos a Vila Velha e a Serra, e o fluxo vindo de Vila Velha em direção a Cariacica.

Os saldos migratórios intra-regionais são mais elevados para Serra (5.745), que apresenta o maior saldo migratório do Estado desde a década de 1970, e Viana (1.976), que recentemente vem se incorporando ao processo de crescimento da região, superando Vila Velha, com números elevados de entradas como de saídas de população. Vitória e Cariacica perdem população nestas trocas internas, com saldos de, respectivamente, - 8.899 e - 1.797.

O terceiro eixo do estudo da mobilidade na RMGV focaliza os deslocamentos pendulares para trabalho que se diferenciam das migrações quanto à natureza e à escala em que se produzem. Esse tipo de mobilidade reflete a concentração da estrutura econômica e o grau de integração existente entre as localidades que compõem a região (IBGE, Censo 2000). Véron (2006, p. 50) destaca que "O compartilhamento do espaço urbano resulta do jogo de forças diversas e antagonistas". Com efeito, o custo da moradia nas áreas onde se concentram as estruturas socioeconômicas resulta na

$\begin{array}{lllll}\text { Caminhos de Geografia } \quad \text { Uberlândia } & \text { v. 20, n. } 72 & \text { Dez/2019 } & \text { p. 33-53 Página } 48\end{array}$


segregação entre trabalho e habitação. Os trajetos da migração e dos deslocamentos que ocorrem na área da metrópole representam estratégias que visam ajustar a evolução das funções urbanas e as condições básicas de vida da população.

Tabela 6 - Migração intra-regional - RMGV - 2005-2010.

\begin{tabular}{|c|c|c|c|c|c|c|c|c|}
\hline \multirow{2}{*}{$\begin{array}{l}\text { Município } \\
\text { de } \\
\text { residência } \\
\text { em } 2010\end{array}$} & \multicolumn{7}{|c|}{ Residência em 31/07/ 2005} & \multirow[b]{2}{*}{ Entradas } \\
\hline & $\begin{array}{l}\text { Cariaci } \\
\text {-ca }\end{array}$ & Fundão & $\begin{array}{c}\text { Guara- } \\
\text { pari }\end{array}$ & Serra & Viana & $\begin{array}{c}\text { Vila } \\
\text { Velha }\end{array}$ & Vitória & \\
\hline Cariacica & - & 32 & 273 & 1.549 & 1.477 & 3.239 & 2.409 & 8.979 \\
\hline Fundão & 87 & - & 16 & 591 & 5 & 82 & 391 & 1.171 \\
\hline Guarapari & 377 & 0 & - & 248 & 139 & 1.066 & 738 & 2.568 \\
\hline Serra & 2.824 & 183 & 159 & - & 322 & 2.222 & 7.567 & 13.277 \\
\hline Viana & 1.941 & 85 & 144 & 374 & - & 785 & 940 & 4.268 \\
\hline Vila Velha & 3.673 & 97 & 560 & 2.026 & 245 & - & 4.397 & 10.998 \\
\hline Vitória & 1.875 & 83 & 597 & 2.744 & 104 & 2.140 & - & 7.543 \\
\hline Saídas & 10.776 & 479 & 1.749 & 7.532 & 2.292 & 9.534 & 16.442 & 48.803 \\
\hline
\end{tabular}

Os deslocamentos para trabalhar em outro município apresentam maior intensidade na RMGV (29,5\% das pessoas que trabalham), comparativamente ao Estado (17,7\%) e ao país (12,8\%) (Figura 7). Esses deslocamentos são mais frequentes para os moradores de Viana e de Cariacica, envolvendo respectivamente 49,5 e 45,5 das pessoas ocupadas destes municípios.

Figura 7 - Deslocamentos de pessoas de 10 anos ou mais para trabalho fora do município de residência Brasil, Espírito Santo, RMGV e municípios - 2010.

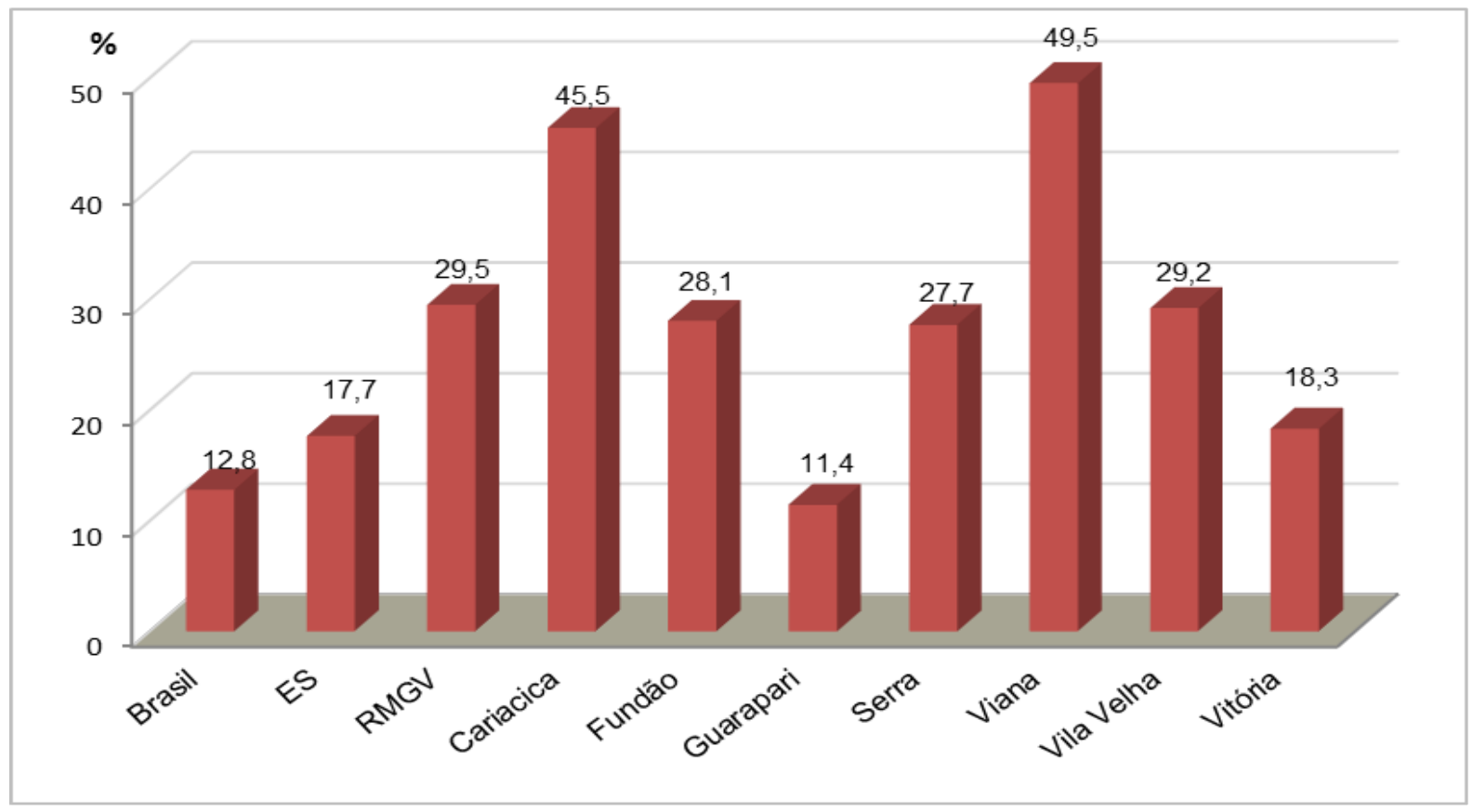

Fonte - Elaborado com dados do IBGE (2012). 
As pessoas ocupadas que se deslocavam para trabalhar em outro município na RMGV em 2010 representavam $78,7 \%$ do total do Estado (IBGE, 2012). A tabela 7 focaliza os fluxos de entradas e saídas para trabalho dos municípios mais populosos da RMGV, destacando os diversos modelos apresentados pelos integrantes da região quanto à intensidade e a direção dos movimentos pendulares para trabalho.

Tabela 7 - Deslocamentos de pessoas de 10 anos ou mais para trabalho fora do município de residência RMGV - 2010.

\begin{tabular}{|l|r|r|r|r|r|r|r|r|}
\hline $\begin{array}{c}\text { Município } \\
\text { de } \\
\text { residência }\end{array}$ & \multicolumn{9}{|c|}{$\begin{array}{c}\text { Município de trabalho } \\
\text { Cariaci- } \\
\text { ca }\end{array}$} & Fundão & $\begin{array}{c}\text { Guara- } \\
\text { pari }\end{array}$ & Serra & Viana & $\begin{array}{c}\text { Vila } \\
\text { Velha }\end{array}$ & Vitória & Outros \\
\hline Cariacica & \multicolumn{1}{|c|}{-} & 20 & 184 & 9.283 & 3.326 & 18.439 & 35.340 & 1.338 \\
\hline Fundão & 48 & - & 7 & 905 & 5 & 49 & 462 & 638 \\
\hline Guarapari & 134 & 0 & - & 176 & 201 & 876 & 1.185 & 1.871 \\
\hline Serra & 2.078 & 356 & 97 & - & 224 & 4.347 & 38.672 & 2.004 \\
\hline Viana & 3.920 & 29 & 110 & 1.027 & - & 2.351 & 5.239 & 294 \\
\hline Vila Velha & 6.374 & 34 & 617 & 6.607 & 896 & - & 35.893 & 1.920 \\
\hline Vitória & 3.631 & 73 & 199 & 11.531 & 894 & 5.695 & - & 2.179 \\
\hline Outros & 359 & 208 & 802 & 961 & 160 & 614 & 4.696 & 10.244 \\
\hline Total & $\mathbf{1 6 . 5 4 4}$ & $\mathbf{7 2 0}$ & $\mathbf{2 . 0 1 6}$ & $\mathbf{3 0 . 4 9 0}$ & $\mathbf{5 . 7 0 6}$ & $\mathbf{3 2 . 3 7 1}$ & $\mathbf{1 2 1 . 4 8 7}$ & $\mathbf{4 1 . 8 4 8}$ \\
\hline & & Fonte - Elaborado com dados do IBGE (2015). & & \\
\hline
\end{tabular}

Vitória, com comportamento particular, é o principal local de trabalho, com saldos positivos com relação a todos os municípios da RMGV, como também ao conjunto dos municípios não metropolitanos. A capital recebe os maiores fluxos da Região, originários de Serra (38.672 Pessoas), Vila Velha (35.893) e de Cariacica (35.340). Um segundo modelo agrupa Vila Velha e Serra que apresentam comportamentos similares: saldos negativos com relação à Vitória, para onde se dirigem fluxos intensos de trabalhadores, e saldos positivos com os outros municípios, mais importantes nas trocas realizadas com Cariacica. O padrão apresentado por Cariacica caracteriza-se pelos maiores saldos negativos do conjunto, sua população é a que mais se desloca para trabalhar em outros municípios, em particular na Capital, em Vila Velha e em Serra.

Pelo volume crescente e por envolverem um grande contingente de população, os deslocamentos pendulares contribuem para determinar o ritmo de vida das aglomerações urbanas (MERLIN, 1997). A análise da dinâmica dos movimentos pendulares mostra que os deslocamentos mais intensos dirigem-se para a principal centralidade do Estado, Vitória e para a área composta pelas unidades que concentram maior população e riqueza e que são mais integradas na região metropolitana.

\section{CONSIDERAÇÕES FINAIS}

O Espírito Santo e sua principal aglomeração urbana apresentam os traços característicos das fases dos processos que marcam a passagem de uma sociedade tradicional, agrícola para o modelo urbano-industrial. $\mathrm{Na}$ fase inicial do período analisado neste trabalho, a população urbana vivia em poucas cidades, sem grande importância, devido à predominância de um modelo de sociedade rural, caracterizado pelo número elevado de pequenos e de médios proprietários e de colonos que praticavam a agricultura familiar dirigida para a cultura do café. Nesse cenário, a mobilidade era restrita às comunidades em que as famílias se inseriam; as taxas de crescimento natural ou vegetativo resultantes de níveis elevados de fecundidade e de declínio da mortalidade determinavam os níveis do crescimento populacional. Os indicadores socioeconômicos e demográficos dos meados do século XX refletem as características marcadamente rurais que persistiram por mais longo tempo

Caminhos de Geografia Uberlândia $\quad$ v. 20, n. $72 \quad$ Dez/2019 $\quad$ p. 33-53 Página 50


no Espírito Santo, comparativamente aos estados da Região Sudeste ou mesmo em relação à média do país.

As décadas de 1960 e 1970 foram caracterizadas por importantes transformações socioeconômicas expressas pela evolução conjunta da transição econômica, passagem da economia agrícola para urbano-industrial, demográfica, marcada pelo declínio da mortalidade e da fecundidade, migratória, na fase de incremento dos fluxos rurais-urbanos, e urbana, com a maioria da população habitando na região urbana. O crescimento natural ou vegetativo inicia sua tendência decrescente e a migração, de tipo "push", muito mais determinada pela repulsão dos fatores da zona rural do que pela atratividade das cidades, passa a ser o principal agente das mudanças demográficas, transferindo a população das regiões rurais e interioranas para a região da capital. A população do Espirito Santo se tornou predominantemente urbana nos anos 1970, tardiamente com relação à Região Sudeste, ocorrida na década de 1950, e no Brasil, na de 1960.

Durante a década de 1980, registra-se a redução no ritmo da migração rural-urbana, quando a pressão demográfica da região rural e das pequenas cidades se atenua, enquanto que a transição demográfica promovia a queda continuada do crescimento natural. Nas últimas décadas o Espírito Santo apresenta características das últimas etapas dos processos transicionais. O ritmo do crescimento demográfico se reduz na população total e nas unidades da principal aglomeração urbana. Na dinâmica migratória, crescem em importância as migrações interurbanas, em particular entre os municípios que compõem a RMGV, tornando-se mais importante que a migração proveniente da zona rural e dos municípios do interior do estado predominante no período de 1950 a 1990 . Da mesma forma, no que concerne à migração interestadual, o perfil do Espírito Santo modifica-se no período analisado, de Estado expulsor de sua população para atrativo, com saldos migratórios positivos, dirigidos majoritariamente para a RMGV, mas também para novas áreas dinâmicas fora do eixo da capital.

Seguindo a tendência postulada pela teoria da transição da migração, surgem novas formas de mobilidade, dentre as quais se observa, na fase atual, a intensificação dos deslocamentos para estudo ou trabalho em outras localidades, sem necessidade de mudança de residência. A capital, Polo da Região, é caracterizada por importante emigração, mas por outro lado, é o centro de atração dos movimentos pendulares dos habitantes da área metropolitana e adjacências.

Dotado de pequeno território densamente povoado, o Espírito Santo apresenta diferenças significativas entre a região da capital (RMGV), e as demais regiões. A principal aglomeração urbana, que concentra população, riqueza, oportunidades socioeconômicas e infraestrutura em geral continua sendo o cenário primordial das transformações que se verificam nas tendências demográficas do Estado. As características, níveis e tendências das transformações demográficas traduzem as desigualdades dos fatores socioeconômicos, políticos e culturais subjacentes aos processos de transição no Espírito Santo, fornecendo indicadores para a elaboração de políticas dirigidas às demandas requeridas pelas diferenciações espaciais como pela modificação dos modos de vida da sociedade.

\section{REFERÊNCIAS}

BAIROCH, P.. De Jéricho à Mexico. Villes et économie dans l'histoire. Paris: Gallimard,1985.

BAENINGER, R. Região, metrópole e interior: espaços ganhadores e espaços perdedores nas migrações recentes - Brasil, 1980-1996. Textos NEPO 35. Redistribuição da população e meio ambiente: São Paulo e Centro Oeste, 3, Campinas, 2000.

BRASIL, G. H.; CASTIGLIONI, A. H.; FELIPE, C. U. Projeções populacionais para o Espírito Santo: 2015-2030. Plano de desenvolvimento: Espírito Santo 2030, Governo do ES, 2013.

BRITO, F.. Urbanização, Metropolização e Mobilidade Espacial da População: Um breve ensaio além dos números. Taller Nacional sobre "Migración interna y desarrollo en Brasil: diagnóstico, perspectivas y políticas", 2007.

CASELLI, G.; VALLIN, J.; WUNSCH, G.. Démographie: analyse et synthèse I - La Dynamique des populations. Paris : INED, 2001.

CASTIGLIONI, A. H.. Migration, urbanisation et développement: le cas de l'Espírito Santo, Bruxelles: CIACO, 1989. 
CASTIGLIONI, A. H.; BRASIL, G. H.. Dinâmica demográfica de Vitória. Projeto da PMV: Agenda Vitória 2008-2028, Prefeitura de Vitória, 2008.

CASTIGLIONI, A. H.. Mudanças na estrutura demográfica do Espirito Santo ocorridas durante a segunda metade do século XX. Revista Geografares, v. 7, p. 93-110, 2009a. https://doi.org/10.7147/GEO7.153

. Migração: abordagens teóricas in ARAGÓN, Luís E. Migração Internacional na PanAmazônia. Belém: NAEA/UFPA, p. 39-57, 2009b.

CASTIGLIONI, A. H. e REGINATO, M.. Impatti socio demografici dell'immigrazione europea in Espirito Santo, in Altreitalie, Rivista internazionale di studi sulle migrazioni italiane nel mondo, n. 38-39/2009, Torino: Rosenberg e Sellier, p. 190-221, 2009.

CARVALHO, J. A. M.; RIGOTTI, J. I. R.. Os dados censitários brasileiros sobre migrações internas : algumas sugestões para análise. Revista Brasileira de Estudos de População, São Paulo, v.15, n. 2, p. 7-16, 1998.

CELIN, J. L. Migração européia, expansão cafeeira e o nascimento da pequena propriedade no Espírito Santo. Dissertação (Mestrado em Economia), Porto Alegre: UFRS, 1984.

COURGEAU, D.. Méthodes de mesure de la mobilité spatiale. Paris:INED,1988.

CUNHA, J. M.P.; PATARRA, N. L. Migração: um tema complexo. Revista São Paulo em Perspectiva, São Paulo, v. 1, n. 2, p. 32-35, jul./set. 1987.

CUNHA, J. M. P. da. Migração e urbanização no Brasil: alguns desafios metodológicos para análise. São Paulo em Perspectiva. v. 19 n. 4, São Paulo, Oct./Dec. 2005. https://doi.org/10.1590/S010288392005000400001

DOTA, E. M.. A migração no Espírito Santo no período 1991-2010: novidades e continuidades. Geografares, p. 142-153, ago. 2016. Disponível em: <http://www.periodicos.ufes.br/geografares/article/view/12001>. Acesso em: 12/09/2016.

GOLINI, A.. La popolazione del pianeta. Bologna:II Mulino, 2003.

IJSN - Instituto Jones dos Santos Neves. Região Metropolitana da Grande Vitória - RMGV. Sistema Gestor e Informações Básicas, Vitória, 2005.

. Produto Interno Bruto (PIB) dos Municípios - 2010, Vitória, 2012.

IBGE- Instituto Brasileiro de Geografia e Estatística. Recenseamento Geral do Brasil ( $1^{\circ}$ de setembro de 1940) - Série Regional - Parte XIV - Espírito Santo, RJ: IBGE, 1951.

IBGE - Conselho Nacional de Estatística. Censo Demográfico 1950, RJ: IBGE, 1955.

IBGE- Fundação Instituto Brasileiro de Estatística. Censo Demográfico de 1960 - Espírito Santo - VII Recenseamento Geral 1960, Série Regional, v. 1, tomo X, RJ, 1968.

. Censo Demográfico - Espírito Santo - VIII Recenseamento Geral 1970, Série Regional, v. 1, tomo XV, RJ, 1973.

IBGE- Fundação Instituto Brasileiro de Geografia e Estatística. Censo Demográfico-dados gerais, migração, instrução, fecundidade, mortalidade, IX recenseamento Geral do Brasil, v. 1, Tomo 4, n . 17, RJ: IBGE, 1982.

.Anuário Estatístico do Brasil, RJ, 1992.

IBGE - Instituto Brasileiro de Geografia e Estatística. Censo demográfico 1991, oㅜ 19, RJ: IBGE, 1996.

Censo demográfico 2000, RJ: IBGE, 2001.

Regiões de influência das cidades 2007. RJ: IBGE, 2008.

Censo demográfico 2010. Resultados Grais da Amostra, RJ: IBGE, 2012.

Censo Demográfico, 2010. Dados da amostra. Disponível em $<\underline{w w w . i b g e . g o v . b r}>$ acesso em 20/08/2015.

Caminhos de Geografia Uberlândia $\quad$ v. 20, n. $72 \quad$ Dez/2019 $\quad$ p. 33-53 Página 52


LANDRY, A. La révolution démographique - Études et essais sur les problèmes de la population. Paris: INED - Presses Universitaires de France, 1982 [1934].

LIRA, P.; OLIVEIRA JUNIOR, A.; MONTEIRO, L. Vitória: transformações na ordem urbana: território, coesão social e governança democrática. Rio de Janeiro: Letra Capital; Observatório das Metrópoles, 2014.

MERLIN, P. Géographie humaine. Paris: PUF, 1997.

NOTESTEIN, F. W. Population,the long view, in: T. SCHULTZ. Food for the world, Chicago: University of Chigaco Press, p. 36-57, 1945.

OLIVEIRA, A. T. R.; ERVATTI, L. R.; O'NEILL, M. M. V. C. O panorama dos deslocamentos populacionais no Brasil: PNADs e Censos Demográficos. In: OLIVEIRA, L. A. P.; OLIVEIRA, A. T. R. Reflexões sobre os deslocamentos populacionais no Brasil. RJ: IBGE, 2011.

PEIXOTO, J.. Dinâmicas e regimes migratórios: o caso das migrações internacionais em Portugal in Análise Social, v. XLII (183), p. 445-469, 2007.

PETRONE, P.. Aspectos geográficos da área de colonização antiga do Estado do Espírito Santo, Vitória: IHGES, 2004.

PUMAIN, D.. Le processus d'urbanisation in CAZELLI, G.; VALLIN, J. et WUNSCH, G. Démographie: analyse et synthèse IV - Les déterminants de la migration, Paris: INED, 2003.

RAVENSTEIN, E.. The Laws of Migration: Second Paper, Journal of the Royal Statistical Society, 52 p. 241-305, 1889. https://doi.org/10.2307/2979333

RIBEIRO, L. C.; MOURA, R.; DELGADO, P.; SILVA, E. Níveis de Integração dos municípios brasileiros em RMs, RIDEs e AUs à dinâmica da metropolização. Relatório de Pesquisa. Rio de Janeiro: Observatório das Metrópoles, 2012.

RIGOTTI, J. I. R.; CAMPOS, J. ; HADAD, R. M.. Migrações internas no Brasil: (des)continuidades regionais à luz do Censo Demográfico 2010. GEOGRAFIAS (UFMG), v. 1, p. 8-24, 2017. https://doi.org/10.5151/socsci-ix-enm-ST1-4

UNITED NATIONS - International Union For The Scientific Study Of Population. Demopædia Dictionnaire démographique multilíngue, seconde édition unifiée, volume français, 2013.

. Department Of Economic And Social Affairs, Population Division. World Urbanization Prospects: The 2014 Revision, New York: United Nations, 2015.

VERON, J.. L'urbanisation du monde. Collection Repères. Paris: La Découverte, 2006.

VRIES J. de. Problems in the measurement, description, and analysis of historical urbanization in WOUDE A. V. D., HAYAMI A. et VRIES, J. de, Urbanization in history, a process of dynamic interactions, Oxford: Clarendon Press, 1995.

ZELINSKY, W.. The Hypothesis of the Mobility Transition. Geographical Review, Vol 61, № 2, p. 219-249, 1971. https://doi.org/10.2307/213996

Recebido em: 26/02/2018

Aceito para publicação em: 26/11/2019 